\author{
RESEARCH ARTICLE \\ 10.1029/2018JE005845 \\ Key Points: \\ - Carbonates mixed with clay \\ minerals can be detected with the \\ use of a unique spectral feature in \\ the 3.40 to $3.80 \mu \mathrm{m}$ range \\ - Carbonates are detected in the \\ middle part of the weathering \\ profiles \\ - Mineralogical associations in the \\ weathering profiles are consistent \\ with weathering by water that \\ contained inorganic carbon species
}

Supporting Information:

- Supporting Information S1

- Table S1

- Figure S1

Correspondence to:

B. Bultel,

benjamin.bultel@geo.uio.no

Citation:

Bultel, B., Viennet, J.-C., Poulet, F., Carter, J., \& Werner, S. C. (2019). Detection of carbonates in Martian weathering profiles. Journal of Geophysical Research: Planets, 124, 989-1007. https://doi.org/10.1029/ 2018JE005845

Received 13 OCT 2018

Accepted 12 MAR 2019

Accepted article online 26 MAR 2019

Published online 17 APR 2019

C2019. American Geophysical Union. All Rights Reserved.

\section{Detection of Carbonates in Martian Weathering Profiles}

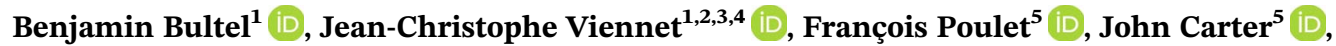 \\ and Stephanie C. Werner ${ }^{1}$ (D) \\ ${ }^{1}$ Centre for Earth Evolution and Dynamics, Department for Geosciences, University of Oslo, Oslo, Norway, ${ }^{2}$ Now at \\ Laboratoire d'Archéologie Moléculaire et Structurale, CNRS UMR 8220, UPMC, Paris, France, ${ }^{3}$ Now at Institut de \\ Minéralogie, Physique des Matériaux et Cosmochimie, IMPMC, Sorbonne Universités, CNRS UMR 7590, Paris, France, \\ ${ }^{4}$ Now at Muséum National d'Histoire Naturelle, MNHN, UPMC, IRD UMR 206, Paris, France, ${ }^{5}$ Institut d'Astrophysique \\ Spatiale, Université Paris-Sud, Orsay, France
}

\begin{abstract}
Noachian surfaces on Mars exhibit vertical assemblages of weathering horizons termed as weathering profiles; this indicates that surface water caused alteration of the rocks that required a different, warmer climate than today. Evidence of this early Martian climate with $\mathrm{CO}_{2}$ vapor as the main component causing greenhouse warming has been challenged by the lack of carbonate in these profiles. Here we report the analysis of Compact Reconnaissance Imaging Spectrometer for Mars L-detector data leading to the detections of carbonates using a spectral signature exclusively attributed to them. The carbonates are collocated with hydroxylated minerals in weathering profiles over the Martian surface. The origin of $\mathrm{CO}_{2}$ for the formation of carbonates could be the atmosphere. The widespread distribution of weathering profiles with carbonates over the surface of the planet suggest global interactions between fluids containing carbonate/bicarbonate ions with the surface of Mars in the presence of atmospheric water until around 3.7 billion years ago.
\end{abstract}

Plain Language Summary The oldest surface of Mars witnessed an impact of dense and humid atmosphere leading to the formation of hydrated minerals. The analysis of remote sensing data allows identifying carbonates mixed with the hydrated minerals. These associations of carbonates and hydrated minerals are widespread on the surface of the planet. This indicates a planetary-scale process of formation involving the presence of fluids containing inorganic carbon. This finding allows a better understanding of the environment of Mars during the period suspected to be the most likely to have host habitable environment on the planet.

\section{Introduction}

Several morphological features (valley networks, Howard et al., 2005; open-basin lakes, Goudge et al., 2012; fluvial pebble conglomerates, Williams et al., 2013) indicate that liquid water once shaped the Martian surface. Moreover, widespread weathering leading to the formation of clay minerals documents that surface water percolated through Martian basaltic rocks (Carter et al., 2013). Among clay minerals formations, Carter et al. (2015) described weathering profiles. Weathering profiles are vertical assemblages of weathering horizons of a few centimeters to near a hundred meters depending on the local climatic conditions. Weathering profiles are open systems affected by percolation of meteoric water. The nature of the weathering profiles is a complex response to climatic and geologic controls and to long-term changes in surface environmental conditions (Pinti, 2011; Velde \& Meunier, 2008). Some weathering profiles on Mars were preserved because they are protected by a datable capping unit made of unaltered volcanic rocks. This allows us to suggest that they formed no later than 3.65 billion years ago (Carter et al., 2015; Loizeau et al., 2012). The most complete weathering profiles are characterized by a sequence of horizons topped with Al-rich clay minerals, overlying Al,Fe-rich clay minerals, and Fe,Mg-rich clay minerals at the bottom (i.e., Carter et al., 2015). Such profiles are better explained by chemical weathering by an acidic fluid (Carter et al., 2015; Gaudin et al., 2011; Loizeau et al., 2012; Zolotov \& Mironenko, 2016). On Earth, such sequences are indicative of humid climates with above-freezing temperatures and sustained precipitation over geological timescales (Allen, 1997; Navarre-Sitchler \& Brantley, 2007). By analogy, meteoric waters (aqueous solution in equilibrium with atmosphere) on Mars must have percolated through the parent rock over millions of years to explain tens of meters thick horizons of clays as suggested by Earth studies (Righi \& Meunier, 1995). However, Bishop et al. (2018) discuss the possibility of forming these profiles with a 
succession of sporadic short-term climate optima producing warm and wet conditions. This would be coherent with impact-induced rainfall (Zolotov \& Mironenko, 2016). If Mars experienced a humid climate for a long time, a dense atmosphere mostly composed of $\mathrm{CO}_{2}$ and lower amounts (few percent) of other greenhouse gasses is required (Wordsworth et al., 2017). Under such climatic conditions, both geochemical models (Schaefer, 1990; Zolotov \& Mironenko, 2016) and laboratory experiments (Gaudin et al., 2018; Viennet et al., 2017) have shown the coprecipitation of hydrated minerals and small amounts of carbonates. Therefore, the apparent absence of carbonates in these weathering profiles remains enigmatic and debates on inhibited formation or subsequent dissolution of the carbonates are yet inconclusive (Edwards \& Ehlmann, 2015). Current carbonate detections on Mars are mostly restricted to subsurface hydrothermal settings implying little to no exchange with the atmosphere (i.e., Wray et al., 2016). Recently, several additional carbonate detections have been reported using Compact Reconnaissance Imaging Spectrometer for Mars (CRISM) near-infrared reflectance data in regions analyzed in our study (Amador et al., 2018), but the methodology of detection precludes a detailed context of the carbonate formation. Furthermore, a limited amount of carbonates, possibly formed by surface weathering or more likely by evaporative precipitation at low temperature, is documented (i.e., Boynton et al., 2009; Morris et al., 2010; Ruff et al., 2014). However, evidence for long-term atmosphere-surface interaction on global scale leading to surface weathering associated with formation of carbonates was lacking.

Here we report the presence of carbonates associated with clay minerals in weathering profiles. This suggests that the alteration fluid, containing inorganic carbon, interacted with the surface of Mars on a planetary scale. In section 2, the method for mineral detection is presented with an emphasis on the carbonates case. We present tests of the method used for the detection of carbonates mixed with hydrated minerals. Section 3 gives an overview of the results obtained from the analysis of the weathering profiles. Then, we focus on three well-preserved sites to describe the weathering profiles in more details. Finally, we discuss the formation process of the weathering profiles and its coherence with the current knowledge on the evolution of Mars.

\section{Method}

\subsection{Data Selection}

For the morphologic characterization of the sites studied, we used high-resolution image data collected by the Context Camera (CTX) and High Resolution Imaging Science Experiment (HiRISE) instruments both on board Mars Reconnaissance Orbiter. Altimetry data are derived from Mars Orbital Laser Altimeter (MOLA, Mars Global Surveyor) data to investigate the stratigraphy of the weathering profiles.

To select the portion of CRISM (Murchie et al., 2007) images to analyze, we relied on the well-documented study of Carter et al. (2015) to choose in the described area from all CRISM images. However, since the identification of carbonates is more difficult with low signal-to-noise ratio (SNR) data, we restrained our search on full-resolution targeted (FRT) data acquired before 2010 (2010 excluded). Nili Fossae has been excluded because in this region carbonates detected were probably formed in a hydrothermal context (Brown et al., 2010; Ehlmann et al., 2008; Viviano et al., 2013). Nevertheless, such area has been used to constrain our new criterion for carbonates detection. The number of CRISM images analyzed is 144 . Table S1 in the supporting information summarizes the data used and the interpretation associated.

\subsection{CRISM Processing}

Using near-infrared spectral data (L-detector) obtained by CRISM on board the Mars Reconnaissance Orbiter, we successfully searched for carbonates within weathering profiles distributed over the Martian surface (Figure 1). The data were collected in the targeted mode in the spectral range of 1.00 to $3.92 \mu \mathrm{m}$, with a spectral resolution of $\approx 6 \mathrm{~nm}$ and a full spatial resolution of $\approx 18 \mathrm{~m} / \mathrm{pixel}$.

All data cubes were downloaded via the MarsSI application (Quantin-Nataf et al., 2018) and processed with CRISM Analysis Toolkit version 7.3.1 (Murchie et al., 2007). This process includes a photometric correction and a "volcano scan" correction for atmospheric gas absorptions (Langevin et al., 2005; McGuire et al., 2009). A spatial and spectral noise removal method is then applied to the data (Parente et al, 2008). The presence of dust on the surface weakens the mineralogical signal. Hence, a median ratio was used to highlight absorptions. Each pixel of a column is divided by the median spectrum calculated from the whole column following 


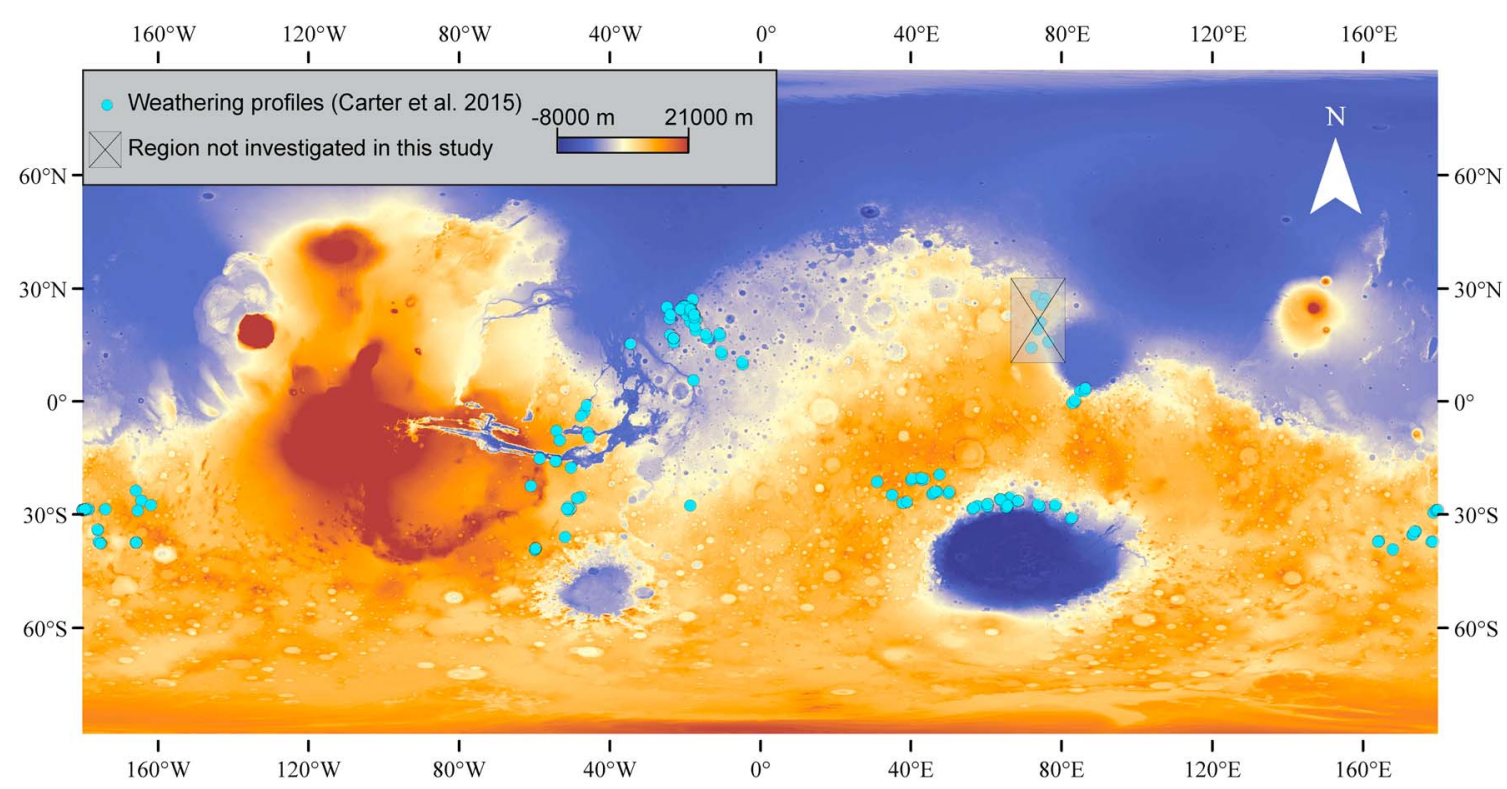

Figure 1. Topographic map from Mars Orbiter Laser Altimeter. The weathering profiles as documented in Carter et al. (2015) are in blue. Note that the weathering profiles in the Nili Fossae region are not investigated here (gray shaded area).

the procedure described in Bultel et al. (2015). All spectra were then analyzed by a minimal spatial median on $5 \times 5$ pixels for each region of interest. The spectral criteria, presented in Table 1, are adapted from Viviano-Beck et al. (2014) to map the signals of interest.

\subsection{Mineral Identification}

The hydrated minerals detected in this study exhibit absorption features in the 1.00 to $4.00 \mu \mathrm{m}$ spectral domain but are typically identified on Mars in the 1.00 to $2.60 \mu \mathrm{m}$ spectral domain (Clark et al., 1990). The absorptions near 1.40 and $1.90 \mu \mathrm{m}$ are common to all hydrated minerals presented here, and they correspond to $\mathrm{H}_{2} \mathrm{O}$ stretching. The absorption near 2.16-2.21 $\mu$ m indicates an $\mathrm{Al}-\mathrm{OH}$ vibration (or $\mathrm{Si}-\mathrm{OH}$, depending on the shape of the absorption), while the absorption near $2.27-2.35 \mu \mathrm{m}$ indicates a (Fe, $\mathrm{Mg}$ )$\mathrm{OH}$ vibration. They usually have weaker overtones near $2.38 \mu \mathrm{m}$ (linked to the $\mathrm{Fe}, \mathrm{Mg}$ ratio) and near

Table 1

Spectral Criteria

\begin{tabular}{|c|c|c|c|c|}
\hline Criterion name & Criterion & Condition & Liaison & Comment \\
\hline $\mathrm{BDa} 2200$ & $1-\frac{R(2.20) \times 2}{R(2.12)+R(2.23)}$ & - & $\mathrm{Al}-\mathrm{OH}$ & Highlights an absorption near $2.20 \mu \mathrm{m}$ \\
\hline $\mathrm{BDa} 2300$ & $1-\frac{R(2.29)+R(2.36)}{R(2.23)+R(2.42)}$ & - & $(\mathrm{Fe}, \mathrm{Mg})-\mathrm{OH}$ & Highlights an absorption near $2.30-2.34 \mu \mathrm{m}$ \\
\hline Carb3900 & $1-\frac{\operatorname{Med}[R(3.81) ; R(3.86)]}{\operatorname{Med}[R(3.54) ; R(3.75)]}$ & $\begin{array}{c}-N a N \text { if } \\
\operatorname{Med}[R(3.54): R(3.75)] \\
>a \\
\times \operatorname{Med}[R(3.81): R(3.86)] \\
+\operatorname{Med}[R(3.81): R(3.86)] \\
\text { or if } \\
\operatorname{Med}[R(3.40): R(3.54)] \\
>\operatorname{Med}[R(3.60): R(3.70)] \\
\text { or if } \\
\operatorname{Med}[R(3.81): R(3.86)] \\
>\operatorname{Med}[R(3.60): R(3.70)]\end{array}$ & $\mathrm{C}-\mathrm{O}_{3}$ & $\begin{array}{l}\text { Highlights a spectrum with a } \\
\text { bulge centered near } 3.60-3.70 \mu \mathrm{m} \text { and a } \\
\text { lowered reflectance near } 3.40-3.50 \\
\text { and } 3.80-3.85 \mu \mathrm{m} \text {. }\end{array}$ \\
\hline
\end{tabular}

Note. $\operatorname{Med}[R(X . X X) ; R(Y . Y Y)]$ is the median of reflectance on all the wavelengths between the two wavelengths indicated. $R(X . X X)$ corresponds to the reflectance at the wavelength $X . X X$. $-\mathrm{NaN}$ corresponds to "not a number." $a$ is a factor that can be adjusted in case of low absorption near $3.50 \mu \mathrm{m}$ or large absorption near $3.00 \mu \mathrm{m}$ hiding the carbonate feature and that is generally lower than 0.1 . 

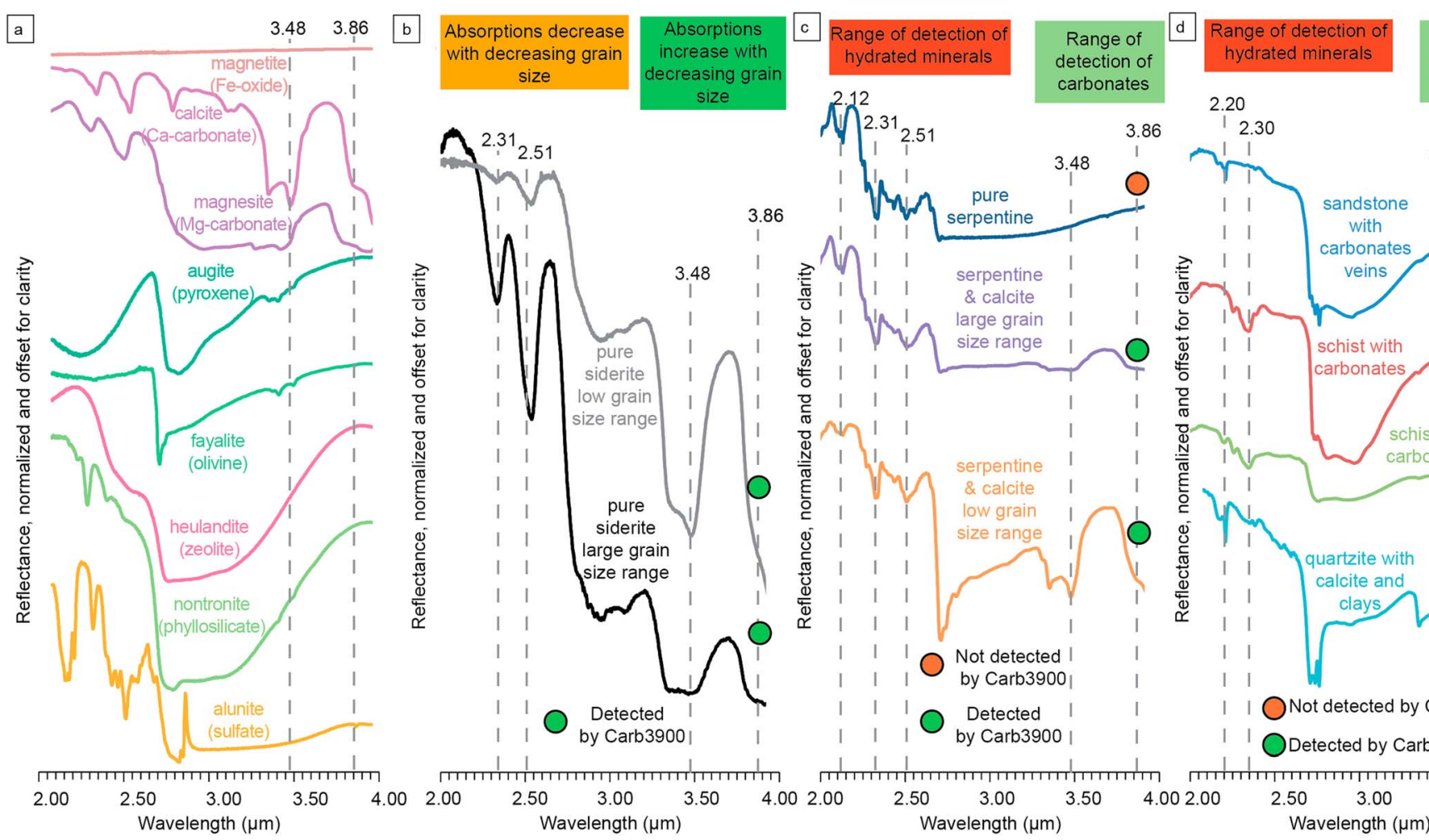

Range of

detection of

carbonates

3.86
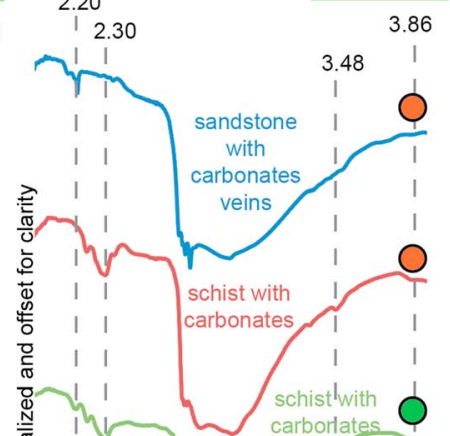

Figure 2. Laboratory NIR (near infrared) spectra highlighting the variations due to grain size range and range of sensitivity for carbonate detection when mixed with clay minerals. The colored circles indicate which spectra are detected by the Carb3900 criterion (green $=$ detected; red $=$ not detected). All the spectra and the mineralogical identification are from the ASTER (Advanced Spaceborne Thermal Emission and Reflection Radiometer) library (Baldridge et al., 2009). (a) Library spectra of magnetite, calcite, magnesite, augite, fayalite, heulandite, nontronite, and alunite. (b) Increase of the relative absorption band depth between the 3.40 to $3.80 \mu \mathrm{m}$ range and the 2.00 to $2.60 \mu \mathrm{m}$ range of pure siderite with the decrease of grain size ranges from $125-500 \mu \mathrm{m}$ (black) to $0-45 \mu \mathrm{m}$ (gray). (c) NIR spectra of serpentine and calcite mixtures. From top to bottom: pure serpentine of 125 to $500 \mu \mathrm{m}$ grain size range, serpentinite with calcite of 500 to $1,500 \mu \mathrm{m}$ grain size range, and serpentinite containing calcite of 0 to $75 \mu \mathrm{m}$ grain size range. (d) Different rock species and carbonates. From top to bottom: sandstone with few veins of carbonates of 0 to $75 \mu \mathrm{m}$ grain size range, schist with $3.6 \%$ of carbonates of 0 to $75 \mu \mathrm{m}$ grain size range, schist with few crystals of carbonates of 500 to $1,500 \mu \mathrm{m}$ grain size range, and quartzite with $25 \%$ of calcite and $2 \%$ of clays of 0 to $75 \mu \mathrm{m}$ grain size range.

$2.50 \mu \mathrm{m}$. These different absorptions and their shapes aid in distinguishing the different phyllosilicates from Al- to Fe,Mg-rich phyllosilicates (Clark et al., 1990; Hunt, 1977). A single absorption near 2.40-2.50 $\mu \mathrm{m}$ relates to $\mathrm{H}_{2} \mathrm{O}$ stretching and $\mathrm{AlCa}-\mathrm{OH}$ bending (Cloutis et al., 2002) or O-H, H-O-H, and S-O vibration (Cloutis et al., 2006) and indicates either zeolite or sulfate. While carbonates were previously identified on Mars by a paired absorption at 2.30 and $2.50 \mu \mathrm{m}$, we searched for a specific absorption pattern in the 3.40 to $3.80 \mu \mathrm{m}$ wavelength range where absorptions band are the deepest (Figures $2 \mathrm{a}$ and $2 \mathrm{~b}$ ). This pattern can be described as reflectance inflections in the 3.40 to 3.50 and 3.80 to $3.90 \mu \mathrm{m}$ ranges combined with higher reflectance near 3.60-3.70 $\mu \mathrm{m}$. Moreover, the first identification of Martian carbonate has been possible thanks to this feature (Ehlmann et al., 2008). Second, such a spectral signature is uniquely explained by $\mathrm{CO}_{3}{ }^{2-}$ overtone vibrations, as documented in numerous laboratory measurements (Gaffey, 1987; Hexter, 1958; Hunt \& Salisbury, 1971). Finally, the presence of absorptions near 3.40-3.50 and 3.80-3.90 $\mu \mathrm{m}$ causing a broad peak near $3.60-3.70 \mu \mathrm{m}$ is systematic in all carbonate spectra for all the particle sizes considered, while it is not the case for the signature at 2.30 and $2.50 \mu \mathrm{m}$ (Figure 2). In the following part we explain why the 3.40 to $3.92 \mu \mathrm{m}$ range is preferred to detect carbonates.

In general, all carbonate spectra have a distinctive signature between 3.40 and $3.80 \mu \mathrm{m}$ corresponding to a bulge-like feature with a maximum at $\sim 3.65$ to $3.70 \mu \mathrm{m}$. This feature is defined as follows in the literature (Cloutis et al., 2002; Hunt \& Salisbury, 1971): a broad spectral peak near $3.60-3.70 \mu \mathrm{m}$, which is due to the deep 3.40 to 3.50 and 3.80 to $3.90 \mu \mathrm{m}$ carbonate bands on either side. The median values of the 
reflectance near 3.40 and $3.80 \mu \mathrm{m}$ are similar. This feature can only be attributed to carbonates $\left(\mathrm{X}^{-} \mathrm{CO}_{3}{ }^{2-}\right.$; Gaffey, 1987; Hexter, 1958; Hunt \& Salisbury, 1971; Hunt, 1977). Among the minerals most commonly found on Mars, which include olivine, pyroxenes, iron oxides, smectites, sulfates, carbonates, and zeolites, the carbonates are the only one to show a clear distinctive feature in the 3.40 to $3.80 \mu \mathrm{m}$ range. The other minerals listed above are showing a constant increase of reflectance from 3.00 to $4.00 \mu \mathrm{m}$ (Figure 2a). Figure $2 \mathrm{~b}$ shows two spectra of pure Fe-carbonate $\left(\mathrm{FeCO}_{3}\right.$ and siderite) of two grain size ranges (0-45 and 125-500 $\left.\mu \mathrm{m}\right)$. Figure 2c presents different spectra of phyllosilicate and carbonate mixtures with different grain size ranges and carbonate contents, as well as a pure serpentine spectrum, for comparison. While the absorptions near

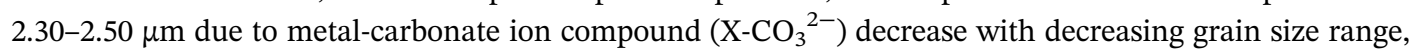
the 3.40 to $3.80 \mu \mathrm{m}$ absorptions due to $\mathrm{C}_{-} \mathrm{O}_{3}{ }^{2-}$ vibrations increase with decreasing grain size range (Figure 2b). This evolution has already been seen by Roush (2010), who showed that a decrease in grain size (from 500 to $<45 \mu \mathrm{m}$ ) causes a decrease of the absorptions near 2.30 and $2.50 \mu \mathrm{m}$, and by Salisbury et al. (1987) and Salisbury and Walter (1989), who showed the amplification of the absorptions near 3.40 and $3.80 \mu \mathrm{m}$. The decrease of the absorptions near 2.30 and $2.50 \mu \mathrm{m}$ with the grain size was also described in Hopkinson et al. (2017) for a grain size range from $<3$ to $121 \mu \mathrm{m}$.

The absorptions obtained on a mixture of phyllosilicates and carbonates are similar to the absorptions of a pure phyllosilicate in the 1.00 to $2.60 \mu \mathrm{m}$ range (Figures $2 \mathrm{~b}$ and $2 \mathrm{c}$ ). The carbonate features, especially in the 1.00 to $2.60 \mu \mathrm{m}$ range, are hidden by the absorption of phyllosilicates (Blaney \& McCord, 1989; Bonello et al., 2004; Salisbury et al. 1987; Salisbury \& Walter, 1989; Sutter et al., 2007, Wagner \& Schade, 1996). Therefore, the identification and the characterization of the metal component in carbonate is not possible (see section 2.6). Sutter et al. (2007) report analysis of samples by infrared spectroscopy in the 1.00 to $4.00 \mu \mathrm{m}$ range. The authors suggest that because of a complex mixing between carbonates, nitrates, sulfates, and phyllosilicates, the carbonate can uniquely be identified based on the $3.90 \mu \mathrm{m}$ band in the spectral range studied. Indeed, the identification of carbonate mixed with various components can be uniquely identified using the 3.40 to $3.80 \mu \mathrm{m}$ feature (Figure $2 \mathrm{c}$ ). This also suggests that the grain size range plays a major role for carbonate absorptions band depth at $2.30-2.50 \mu \mathrm{m}$ (respectively at $3.40-$ $3.80 \mu \mathrm{m}$ ), which decreases (respectively increasing) with the decrease of the grain size range. Using such an absorption range $(3.40-4.00 \mu \mathrm{m})$, Wagner and Schade (1996) suggest that more than $15 \mathrm{wt} \%$ of siderite mixed with palagonite (with a grain size $<25 \mu \mathrm{m}$ ) is needed to allow making the bands due to carbonates visible in their study. Therefore, in the present study, the identification of carbonate is based on the shape of the spectra between 3.40 and $3.80 \mu \mathrm{m}$. Based on these specific signatures, we developed a spectral parameter to identify and map carbonates. We defined the spectral criterion Carb3900 to detect carbonate, which focused on the signal between 3.40 and $3.80 \mu \mathrm{m}$ with a similar value for the medians of the reflectance intensity near 3.40 and $3.80 \mu \mathrm{m}$ and a higher value for the median of the reflectance intensity near 3.60-3.70 $\mu \mathrm{m}$. In section 2.4, we detail the validation of this spectral identification by comparison with previous carbonate detections in Nili Fossae (Ehlmann et al., 2008). Moreover, we have verified the presence of this $\mathrm{CO}_{3}{ }^{2-}$ signature by using overlapping CRISM spectral images in order to discard any possible artifacts at such positions (see section 2.5).

\subsection{Carbonate Detection Validation at Nili Fossae}

To further test whether the Carb3900 criterion is able to detect carbonates on previous detections (Ehlmann et al., 2008), we analyzed the CRISM data FRT0000B072 (Figure 3). The mineralogical maps compare the detection for the carbonate criteria described by Viviano-Beck et al. (2014), referred to as MIN2295_2480 (Figure 3a) and MIN2345_2537 (Figure 3a); BDCARB (Pelkey et al, 2007; Figure 3c), used in most of the publications with detections of carbonates on Mars with CRISM (Harner \& Gilmore, 2015; Viviano et al., 2013; Wray et al., 2016); and Carb3900 (Figure 3b), newly used in this study. An RGB image is also present (Figure 3d) to help with the comparison. While the MIN2295_2480, MIN2345_2537, and BDCARB criteria are focusing on the absorptions near $2.30-2.50 \mu \mathrm{m}$, the Carb3900 criterion is focusing on the presence of a spectral feature near 3.40-3.80 $\mu \mathrm{m}$. The criterion BDCARB highlights the carbonates; however, it contains false positives (see Viviano-Beck et al., 2014). Therefore, the MIN2295_2480 and MIN2345_2537 criteria are used here for the comparison. While the areas highlighted by the Carb3900 criterion are smaller than the one of the MIN2295_2480 or MIN2345_2537 criteria, there is no new area highlighted via the Carb3900 criterion. This is an illustration of how our criterion is more restrictive. The results displayed in 

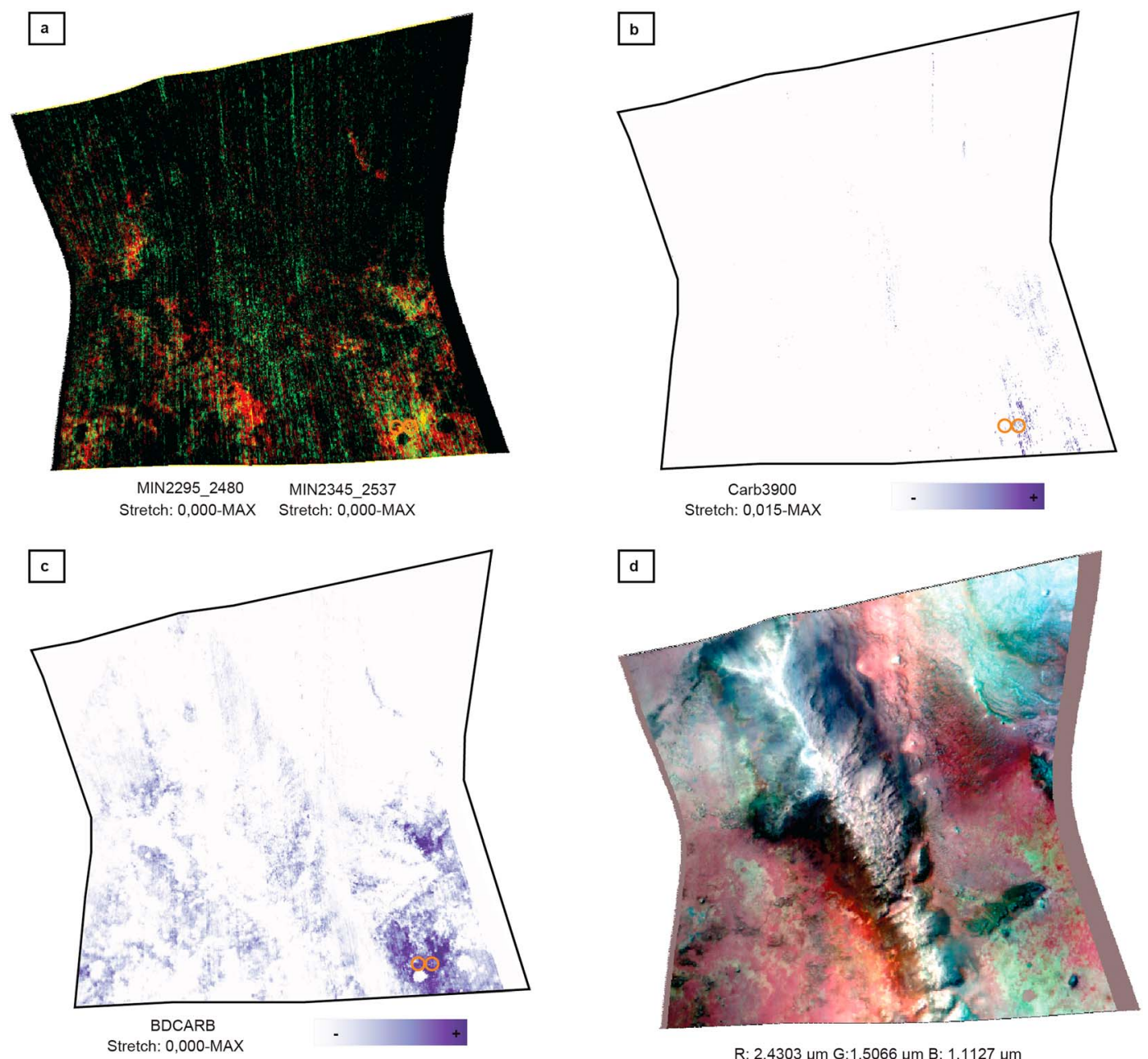

Figure 3. (a) Color composite on CRISM cube FRT0000B072 with the following: in red, MIN2295_2480 and in green, MIN2345_2537 (Viviano-Beck et al., 2014) highlighting carbonates. (b) Criterion Carb3900 on CRISM cube FRT0000B072 highlighting carbonates. (c) Criterion BDCARB on CRISM cube FRT0000B072. (d) RGB composite on CRISM cube FRT0000B072 with the following: in red, 2,4303 $\mu \mathrm{m}$; in green, 1,5066 $\mu \mathrm{m}$; in and blue, 1,1127 $\mu \mathrm{m}$.

the maps confirm that the 3.40 to $3.80 \mu \mathrm{m}$ feature highlighted by the Carb3900 criterion is linked to carbonate detections made in previous studies with BDCARB (Ehlmann et al., 2008). This example shows the ability of our criterion to map the presence of carbonates in places on Mars with earlier confident carbonate detections.

To understand why the Carb3900 criterion is more restrictive than are the MIN2295_2480 and MIN2345_2537 criteria, Figure 4 shows two spectra acquired in the Nili Fossae region from the image of Figure 3. The light green spectrum, identified as carbonates, is highlighted only by the MIN2295_2480 and MIN2345_2537 criteria. The light green spectrum, while having absorptions at 2.30, 2.51, and $3.80 \mu \mathrm{m}$ and being detected with the MIN2295_2480 and MIN2345_2537 criteria, cannot be interpreted as carbonate with the Carb3900 criterion because of the missing clear 3.40 to $3.80 \mu \mathrm{m}$ carbonate absorption shape. Indeed, a clear absorption near $3.40 \mu \mathrm{m}$ is missing, and the reflectance at $\sim 3.40-3.50 \mu \mathrm{m}$ is higher than the reflectance at $\sim 3.80-3.85 \mu \mathrm{m}$. The lack of feature at $\sim 3.40 \mu \mathrm{m}$ could be explained here by the presence of water, coatings, or mixture with other minerals as explained in Ehlmann et al. (2008). The light blue spectrum is interpreted as carbonates probably mixed with phyllosilicates (absorptions near 1.90 and $2.38 \mu \mathrm{m}$ ) with the Carb3900 and MIN2295_2480 and MIN2345_2537 criteria. Finally, the 


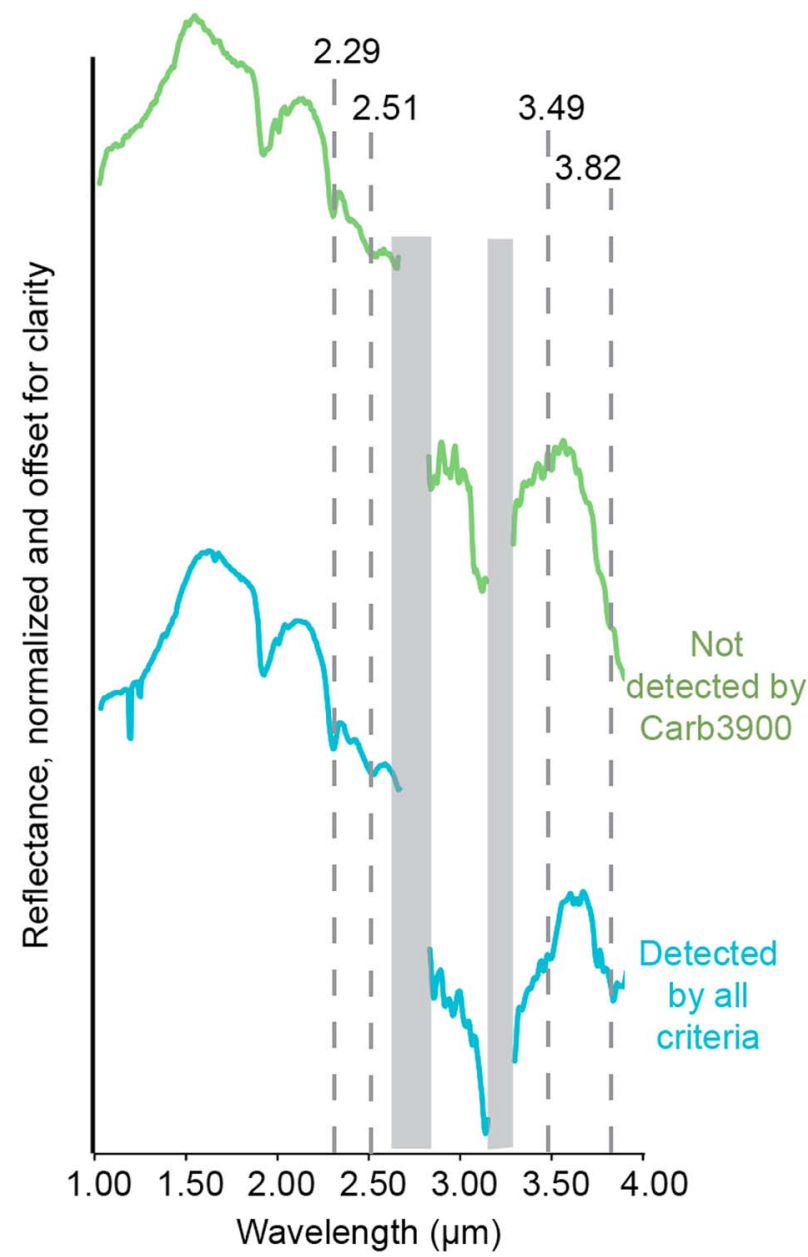

Figure 4. Spectra acquired on the CRISM cube FRT0000B072. The light green spectrum is from X: $602 \mathrm{Y}: 638$ [20 $202 \mathrm{AVG}]$. This ROI is highlighted on the map for all the criteria except Carb3900. The light green spectrum is detected only with the BDCARB, MIN2295_2480, and MIN2345_2537 criteria, while the light blue spectrum is detected with all the criteria used here. The light blue spectrum is from X: 639 Y: 654 [20 $\times 20$ AVG] (with projection). This ROI is highlighted on the map for all the criteria. The gray areas hide artifacts.
Carb3900 criterion appears more restrictive as it needs a clear carbonate absorption shape in the 3.40 to $3.80 \mu \mathrm{m}$ spectral range. This also explains why the mapping with Carb3900 reveals a smaller spatial extent of carbonates (Figure 3).

\subsection{Detection Validation at Studied Areas}

To verify the consistency of the acquired signal (especially after $3 \mu \mathrm{m}$ ), data for which two CRISM data cubes overlapped during two different orbits were compared. This approach evaluates the possible instrumental artifacts and any potential degrading process of instrument. The consistency of the signal over the entire spectral range of the CRISM L (long) channel $(1.00$ to $3.92 \mu \mathrm{m})$ is confirmed by the superimposition of the spectra obtained (see Figures 5 and 6, and Table S2 illustrate the regions of Mawrth Vallis, North Hellas, and Eridiana Basin). Since the signal is consistent on the entire CRISM L spectral range, it demonstrates that the signal is related to characteristics of the surface itself (i.e., absorption due to interaction of the incident beam and mineral structures). Specifically, a co-occurrence of the 3.40 to $3.80 \mu \mathrm{m}$ feature with the detection of weathering products is observed over Mawrth Vallis (Figure 5) while being systematically absent on nonaltered surfaces. Hence, this feature is an alteration product and is interpreted as carbonate.

Using two other examples within the sites of Eridania Basin and North Hellas, we compare different spectra obtained on the same coordinates with different CRISM acquisition characteristics (Figure 6). On the data from North Hellas (Figure 6a), the acquisitions are separated by 2 months, which explain the similarities of the two spectra. The same absorptions near $1.40,1.90,2.30$, and possibly near $3.80 \mu \mathrm{m}$ are visible. Note that the absence of a clear feature near 3.40 prevents the interpretation of carbonate signature. For Eridania Basin (Figure 6b), compared with for North Hellas, the larger difference in date of acquisition (1 year) led to a larger dissimilarity in the signal. However, as for the previous case, the same absorptions are visible. Those examples point out the consistency on the signal on the entire range of the CRISM L channel (1.00 to $3.92 \mu \mathrm{m})$ as a function of time.

\subsection{The Challenge of the Carbonate Composition Characterization}

Theoretically, the cation bonded to the $\mathrm{CO}_{3}{ }^{2-}$ ion can be identified based on the position of the bands near 3.40 and $3.90 \mu \mathrm{m}$ (i.e., De Angelis et al., 2019). These features have recently been used to identify carbonate composition detected on Ceres (Carrozzo et al., 2018; De Sanctis et al., 2015, 2016; Palomba et al., 2017). The distinction between different carbonate compositions can be done by determining the centers of absorptions near 3.40-3.50 and 3.90-4.00 $\mu \mathrm{m}$. However, in the CRISM data, the right shoulder of the absorption near $3.90 \mu \mathrm{m}$ is not visible, and only the position near 3.40-3.50 $\mu \mathrm{m}$ could be used. A center of absorption near $3.42 \mu \mathrm{m}$ would be interpreted as a Mg-rich carbonate, near 3.45-3.50 $\mu \mathrm{m}$ as a Ca- or Fe-rich carbonate, and near 3.50 as a Na-rich carbonate. The presence of the other center of absorption near 3.90-4.00 $\mu \mathrm{m}$ is helping to clearly make the distinction. Distinguishing between $\mathrm{Ca} / \mathrm{Fe}$ and $\mathrm{Na}$-carbonates requires information on the position of the center of absorption near 3.90-4.00 $\mu \mathrm{m}$, which is not completely covered here. Only Mg-rich carbonates could then be clearly identified. However, in case of a mixture with hydrated/hydroxylated minerals, the presence of a strong absorption near $3.00 \mu \mathrm{m}$ (whose shape depends on the nature of hydrated/hydroxylated mineral present in the mixture) disturbs the position of the center of the absorption near 3.40-3.50 $\mu \mathrm{m}$ and hinders any characterization of the carbonate composition. Therefore, our study focuses on the detection of a spectral feature characteristic of carbonates and not on the characterization on the carbonate composition. 

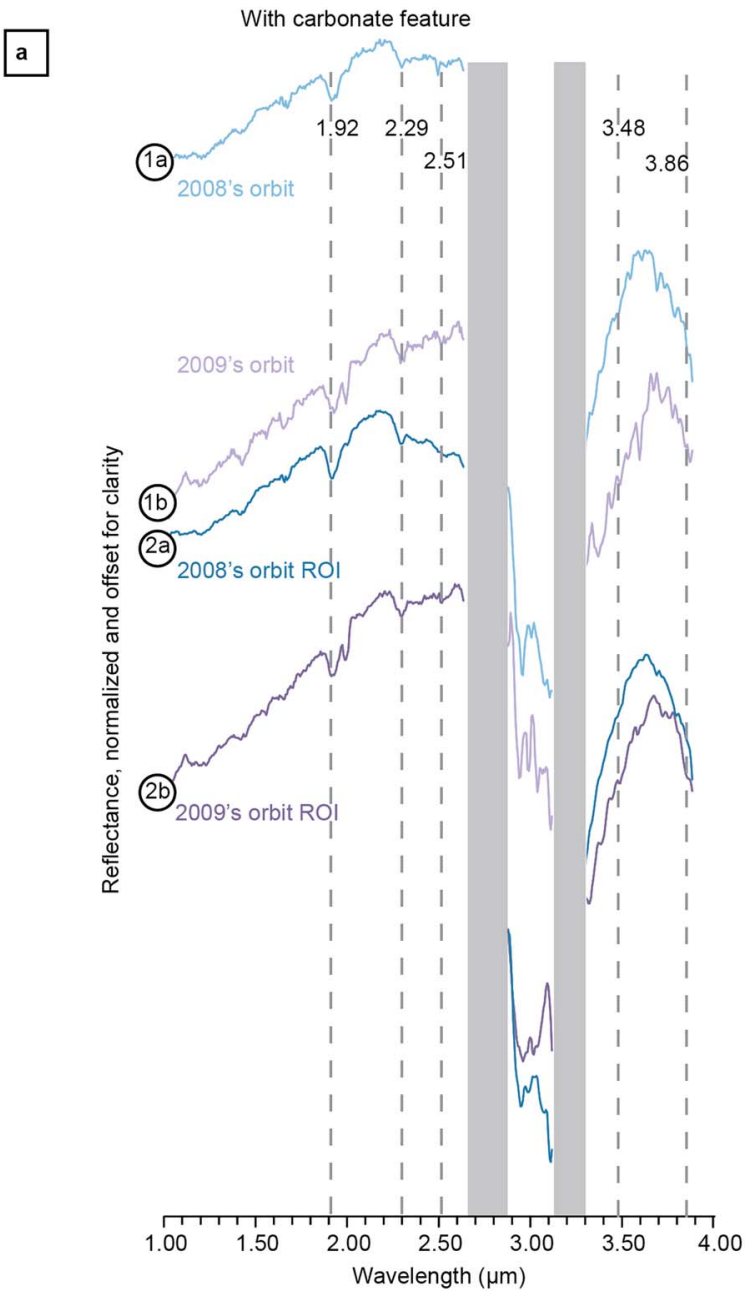

Without carbonate feature

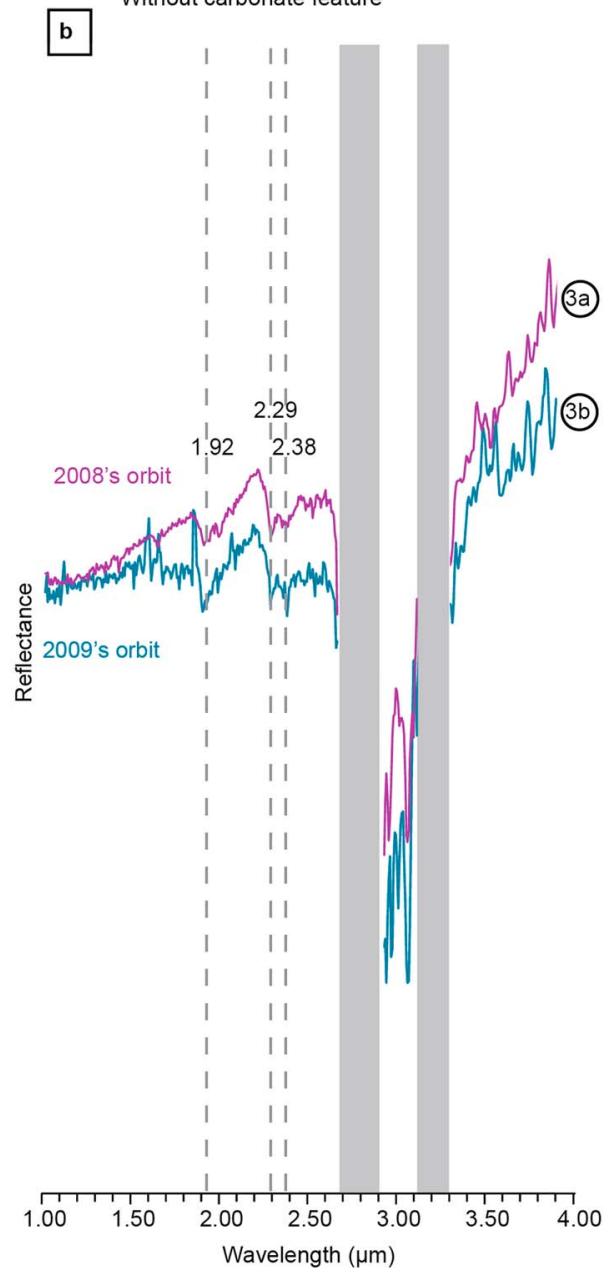

Figure 5. Spectra obtained on two different CRISM cubes for the same coordinates over the Mawrth Vallis region between 2008 and 2009. (a) Spectra highlighting the presence of carbonate features on the 3.40- to $3.80-\mu \mathrm{m}$ range for both orbital measurements. The blue spectra are from FRT0000AA7D (acquired in 2008), while the purple are from FRT000109E0 (acquired in 2009). (b) Spectra of clays without carbonate features at $\sim 3.40-3.80 \mu \mathrm{m}$. The gray areas hide artifacts. Spectra obtained on two different CRISM images of the same surface both with an area of $5 \times 5$ pixels and with a region of interest of more than thousands of pixels. All the coordinates are given in Table S2.

\section{Results}

\subsection{Composition and Occurrence of the Weathering Profiles}

We describe in this paragraph the common spectral characteristics of the apparent stratigraphy (see spectra in Figure 7). All the horizons of the weathering profiles have absorptions near 1.40 and $1.90 \mu \mathrm{m}$, both correspond to the presence of hydrated minerals. They differ only in the 2.10 to $2.60 \mu \mathrm{m}$ range and in the 3.40 to $3.80 \mu \mathrm{m}$ range. The following description focused on these two ranges to identify minerals present in the weathering profiles. The weathering profiles are characterized by a top horizon of Al-rich clay minerals having diagnostic absorption near 2.16-2.21 $\mu \mathrm{m}$, indicating an Al-OH vibration liaison. The horizon beneath has the same absorption near $2.20 \mu \mathrm{m}$ and an additional feature in the 3.40 to $3.80 \mu \mathrm{m}$ spectral range diagnostic of a C- $\mathrm{O}_{3}{ }^{2-}$ vibration liaison. This horizon can be interpreted as a mixture of Al-rich clay minerals and carbonates. It overlies a horizon having a pair of absorptions near 2.20 to $2.30 \mu \mathrm{m}$ diagnostic of a combination of $\mathrm{Al}-\mathrm{OH}$ and $\mathrm{Fe}-\mathrm{OH}$ vibrations liaisons. It is frequently associated with an additional feature in the 3.40 to $3.80 \mu \mathrm{m}$ spectral range. This horizon is interpreted as composed of Al,Fe-rich clay minerals mixed with carbonates when having a diagnostic feature near 3.40-3.80 $\mu \mathrm{m}$. The horizon beneath has absorption near 2.27-2.32 $\mu \mathrm{m}$ diagnostic of (Fe,Mg)-OH vibration liaison and a feature near 3.40-3.80 $\mu \mathrm{m}$. It is interpreted 

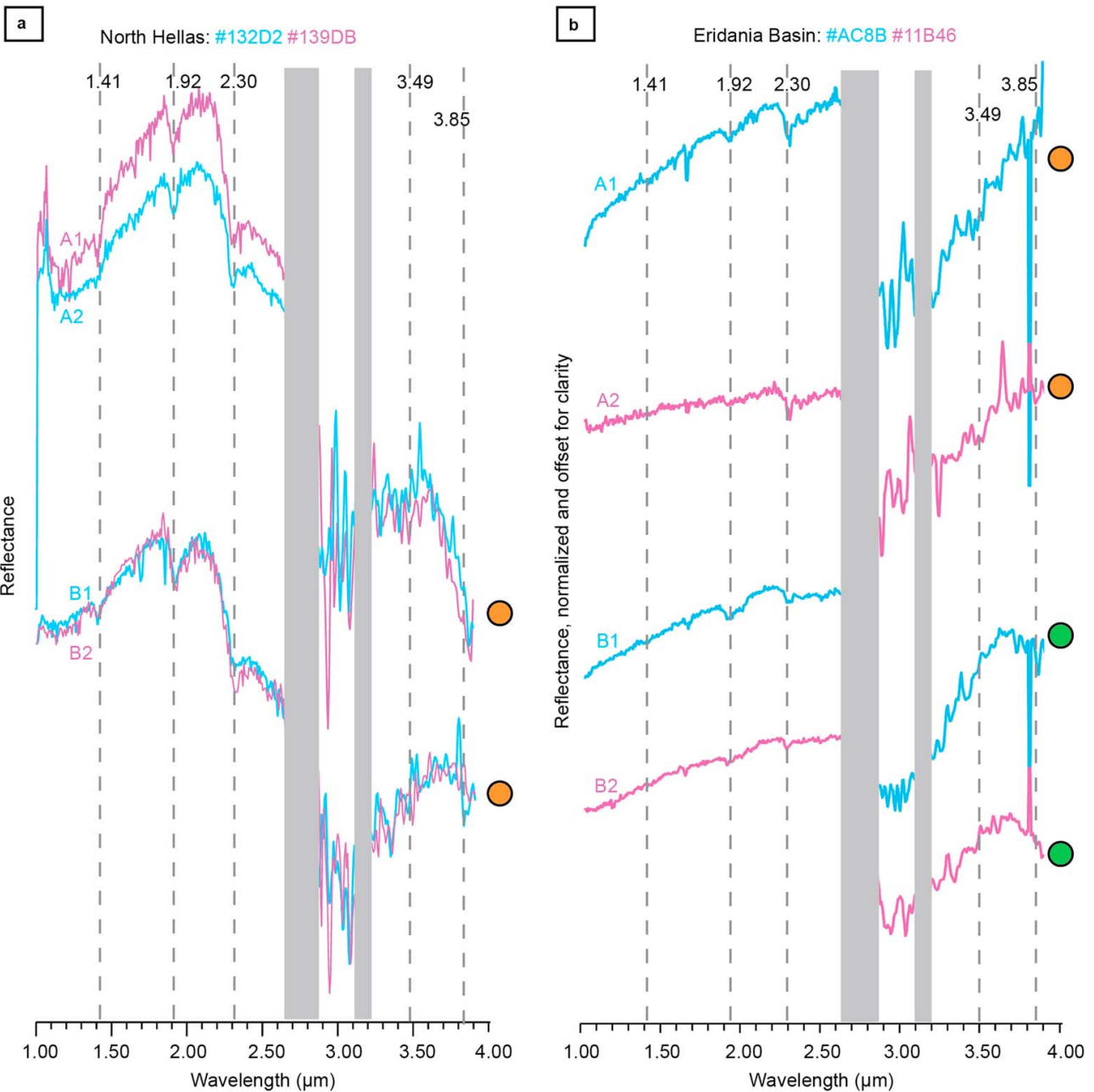

Figure 6. (a) CRISM spectral data over the North Hellas site obtained with 2 months of difference between the acquisitions (from top to bottom: A1 = \#139DB; A2 = \#132D2; B1 = \#132D2; B2 = \#139DB). (b) CRISM spectral data over the Eridania Basin site obtained with 1 year of separation of acquisition (from top to bottom: A1 = \#AC8B; A2 = \#11B46; $\mathrm{B} 1=\# \mathrm{AC} 8 \mathrm{~B} ; \mathrm{B} 2=\# 11 \mathrm{~B} 46)$. All the coordinates are given in Table S2. The gray areas hide artifacts. The colored dots are present if carbonates are detected (orange $=$ no; green $=$ yes).

as a mixture of Fe,Mg-rich clay minerals with carbonates. Finally, the bottom horizon presents an absorption near 2.27-2.32 $\mu \mathrm{m}$, which is interpreted as a horizon composed of Fe,Mg-rich clay minerals. In the Eridania Basin region, an additional bottom horizon can be present. It only presents a spectral shoulder near $2.50 \mu \mathrm{m}$ in the 2.10 to $2.60 \mu \mathrm{m}$ spectral range (only shown with Eridania Basin here but also described in Mawrth Vallis by Bishop et al., 2013). This can be interpreted as a sulfate or a zeolite signature. The top part of this horizon is associated with a feature near 3.40-3.80 $\mu \mathrm{m}$, indicating the presence of carbonates.

Our investigation confirms the sequence of mineral assemblages described by previous authors (Carter et al., 2015). We additionally identified carbonates by the signature in the 3.40 to $3.80 \mu \mathrm{m}$ spectral range in association with parts of the stratigraphic sequence. Indeed, the weathering profiles exhibit different horizons from top to bottom composed of Al-rich clay minerals, a mixture of Al-rich clay minerals and carbonates, $\mathrm{Al}, \mathrm{Fe}-$ rich clay minerals mixed with carbonates, Fe,Mg-rich clay minerals mixed with carbonates, and finally, Fe, Mg-rich clay minerals.

The weathering profiles studied here are classified into three categories depending on their degree of preservation evaluated from a spectroscopic point of view. When exhibiting all the horizons, they are classified as a clear and complete stratigraphy (53 cubes). Because of erosion, some profiles exhibit only the bottom part of 


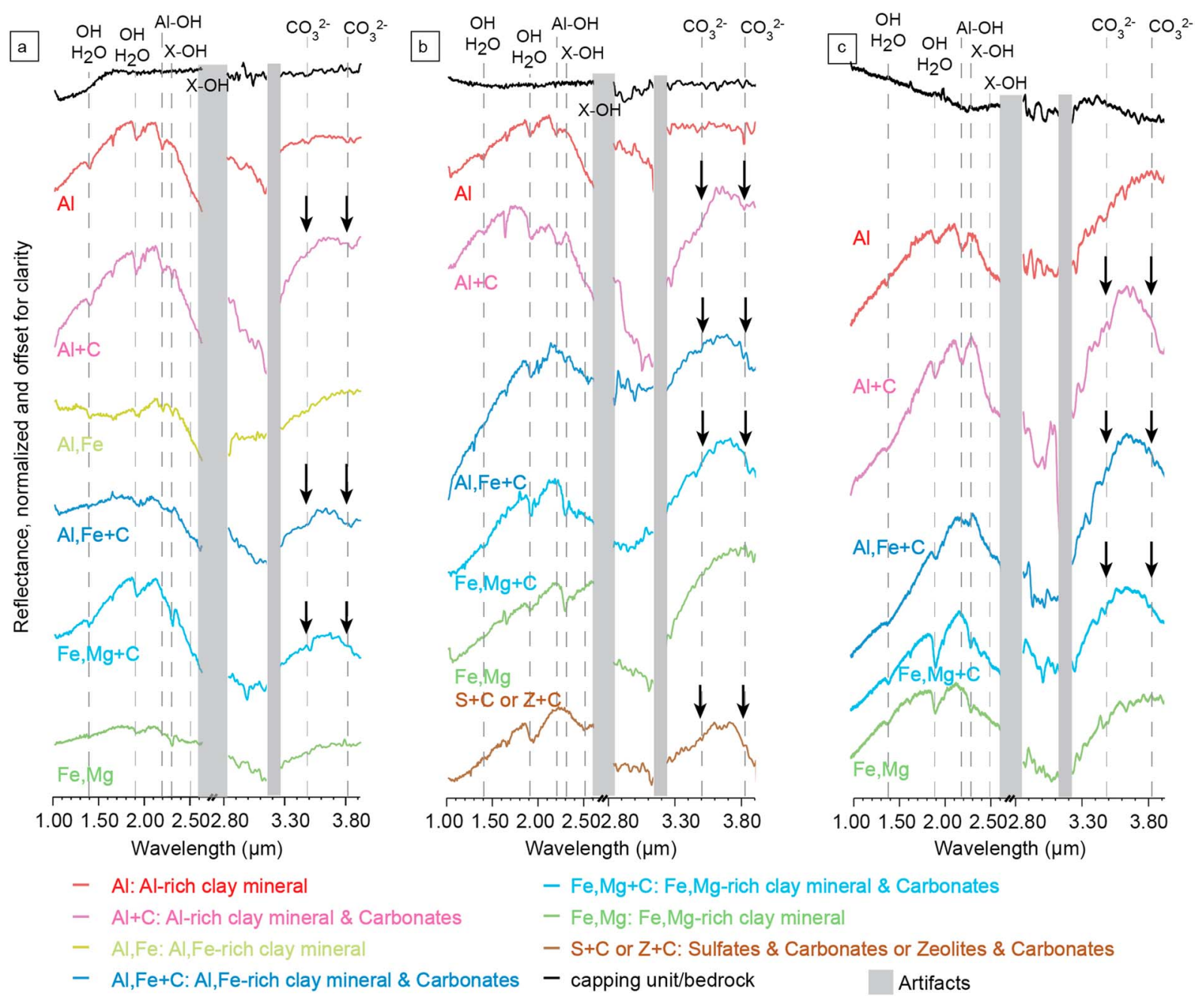

Figure 7. (a) CRISM data from FRT0000A2B8 for the North Hellas region. (b) CRISM data from FRT000092F7 for Eridania Basin. (c) CRISM data from FRT00003BFB for Mawrth Vallis. The reflectance between 1.00 and $2.60 \mu \mathrm{m}$ is shifted compared with the 2.80 to $3.90 \mu \mathrm{m}$ range for visual clarity. From top to bottom: black spectra correspond to unaltered material; red spectra, Al-rich clay minerals; purple spectra, Al-rich clay minerals and carbonates; blue spectra, Al,Ferich clay minerals and carbonates; cyan spectra, Fe,Mg-rich clay minerals and carbonates; green spectra, Fe,Mg-rich clay minerals; and brown spectra, sulfates and carbonates or zeolites and carbonates. Note that the color code used is the same as in Figures 8 and 9. The dashed lines indicate the position and interpretation of the absorptions (X corresponds to Fe or $\mathrm{Mg}$ ) and are located at 1.39, 1.90, 2.19, 2.29, 2.50, 3.49, and $3.82 \mu \mathrm{m}$. The gray areas cover spectral ranges of strong atmospheric absorption near 2.60-2.80 $\mu \mathrm{m}$ and an instrumental artifact at $\sim 3.2 \mu \mathrm{m}$. The site coordinates of spectra are given in Table S3.

the stratigraphy (i.e., the top corresponding to Al-rich clay minerals without carbonate, a mixture of Al-rich clay minerals and carbonates, and Al,Fe-rich clay minerals mixed with carbonates is eroded). They are classified as having a partial stratigraphy (31 cubes). The third categories (60 cubes) concern the weathering profiles that do not exhibit a clear and complete or partial stratigraphy from a spectroscopic point of view (blue dots in Figure 8). The quality of these CRISM data allows us only to confirm the presence of Fe,Mg-rich clay minerals, although the morphology of the profile could indicate the presence of the top of the stratigraphy (Carter et al., 2015). In these cases, the signal was too noisy to allow a confident interpretation of the evolution of the profile mineralogy or any evidence of carbonate. Therefore, they were considered as not exhibiting any stratigraphy. However, the lack of confident detections of the top part of the stratigraphy or of the carbonate feature could be due to the low SNR. Table 2 summarizes the results sorted by region, and a more detailed table sorted by CRISM cubes is presented in the supporting information (Table S1). In the supporting information, we describe in more details the different aspects of the profiles for each region and their degree of preservation. As shown in Figure 8, the first two categories are widespread on the surface of the planet and can be sorted into the following regions: North Hellas, North Argyre, Eridania Basin, Mawrth Vallis, Oxia Planum, Shalbatana 


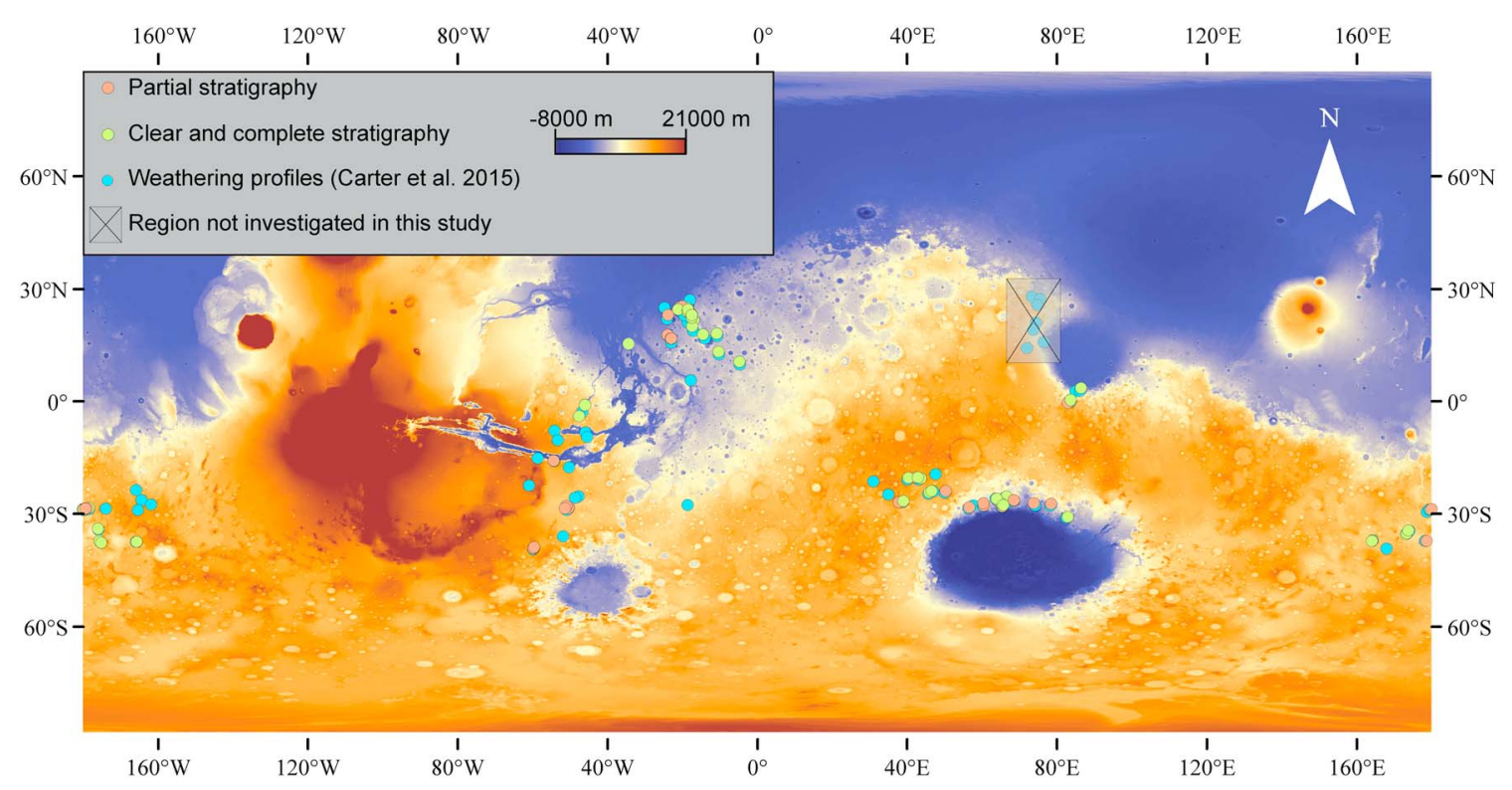

Figure 8. Topographic map from Mars Orbiter Laser Altimeter. The weathering profiles as documented in (Carter et al., 2015) are in blue. Clear and complete stratigraphies of this study are shown in green, while the partial stratigraphies detected are in orange. Note that the weathering profiles in the Nili Fossae region are not investigated here (gray shaded area).

Valley, Libya Montes, and South Coprates. Except in the region of Coprates Chasma, all the regions studied exhibit at least one example of clear and complete stratigraphy. The lack of CRISM data coverage and the low SNR of the data present in the Coprates Chasma region allow us to detect a partial stratigraphy. It appears that regions being both (i) the most covered by CRISM data and (ii) the most preserved are Mawrth Vallis, Eridania Basin, and North Hellas. In the following section, we focus on the three best preserved regions to describe in more detail the local variation in the mineralogy.

\subsection{The Best Preserved Weathering Profiles}

We report here the results on portions of three of the regions investigated. They represent the best preserved sites: North Hellas (i.e., Carter et al., 2015), Eridania Basin (i.e., Carter et al., 2015), and Mawrth Vallis (i.e., Loizeau et al., 2012). The spectra are summarized in Figure 7. In this section, the presence of carbonates is implied by the presence of the feature in the 3.40 to $3.80 \mu \mathrm{m}$ range as explained in section 2 . This feature consists of a high reflectance near 3.65 to $3.70 \mu \mathrm{m}$ compared with the reflectance near 3.40 and $3.80 \mu \mathrm{m}$. The characterization of the clay minerals is based on the methodology described in section 2.3. We describe some individual variations in the mineralogy, as follows:

1. The North Hellas region (Figures 7 and 9): The carbonate feature (in the 3.40 to $3.80 \mu \mathrm{m}$ range) is visible locally in the horizons composed of Al-rich, $\mathrm{Al}, \mathrm{Fe}-$ rich, and $\mathrm{Fe}, \mathrm{Mg}$-rich clay minerals. For the unaltered rock below, the spectrum is featureless in the 2.80 to $3.92 \mu \mathrm{m}$ range, implying the absence of carbonates.

Table 2

The Numbers of Cubes Investigated Are Sorted by Regions

\begin{tabular}{lcccc}
\hline Region names & $\begin{array}{c}\text { Clear stratigraphy } \\
\text { (number of cubes) }\end{array}$ & $\begin{array}{c}\text { Partial stratigraphy } \\
\text { (number of cubes) }\end{array}$ & $\begin{array}{c}\text { No stratigraphy } \\
\text { (number of cubes) }\end{array}$ & $\begin{array}{c}\text { Total investigated } \\
\text { (number of cubes) }\end{array}$ \\
\hline North Hellas & 10 & 13 & 18 & 41 \\
North Argyre & 1 & 0 & 5 & 6 \\
Eridania Basin & 14 & 6 & 11 & 31 \\
Mawrth Vallis & 22 & 2 & 13 & 37 \\
Oxia Planum & 1 & 3 & 3 & 7 \\
Shalbatana Valley & 3 & 0 & 0 & 6 \\
Libya Montes & 2 & 1 & 3 & 13 \\
South Coprates & 0 & 6 & 7 & \\
\hline
\end{tabular}



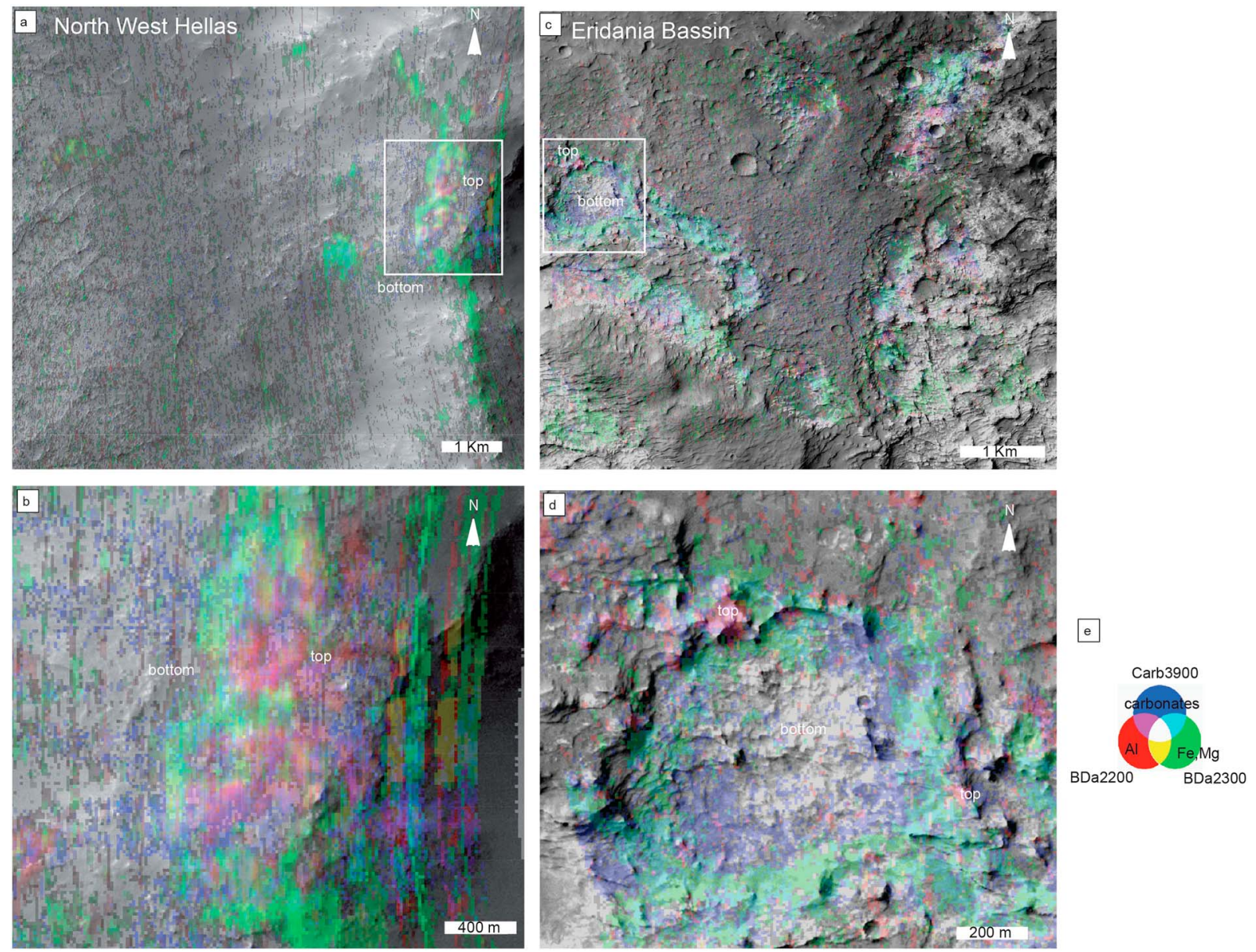

Figure 9. (a) CTX mosaic on North West Hellas with overlapping CRISM image FRT0000ACB8. The white rectangle is for the zoom in (b). (b) Zoom on (a). (c) CTX mosaic on Eridania Basin with overlapping CRISM image FRT000092F7. The white rectangle is for the zoom in (c). (d) Zoom on (c). (e) Schematic color code of the mineral mapping $($ red $=$ Al-rich clay minerals; green $=(\mathrm{Fe}, \mathrm{Mg})$-rich clay minerals; blue $=$ carbonates $)$ with the associated spectral parameters .

2. The Eridania Basin region (Figures 7 and 9): The sequence possesses a top horizon composed of Al-rich clay minerals. An Al,Fe-rich clay mineral horizon is occasionally present beneath, and the carbonate feature is associated in parts of this horizon. Below, an Fe,Mg-rich clay mineral horizon, exhibiting often the carbonates signature, is present. The bottom horizon, which is mixed with carbonates at its top, is composed of sulfates or zeolites. The unaltered surface with featureless spectrum is also visible (no carbonate features).

3. The Mawrth Vallis region (Figures 7 and 10): The top horizon composed of Al-rich clay minerals is better preserved and both laterally and vertically more extended compared with the other two sites. It overlies a horizon of Al-rich clay minerals mixed with carbonates. Below, the horizon composed of Al,Fe-rich clay minerals is mixed systematically with carbonates, while the horizon composed of $\mathrm{Fe}, \mathrm{Mg}$-rich clay minerals below is mixed with carbonates at its top only. This stratigraphic sequence is in many places still protected by a capping unit, likely responsible for the good preservation. This complete and most representative sequence seen at Mawrth Vallis contains carbonates in mixture in its middle part, leaving the top and bottom of the sequence without carbonates.

Of note, on all sites a nonaltered surface or horizon is present and shown for reference (Figure 7). Unlike the altered material, they neither exhibit the carbonate feature at 3.40-3.80 $\mu \mathrm{m}$ nor hydrated minerals in the 1.90 to $2.50 \mu \mathrm{m}$ range.

Because the sites of North Hellas and Eridania Basin are not covered by a capping unit, they were less preserved. However, in some parts, it is still possible to visualize the sequence from Al-rich clay minerals to Fe, 

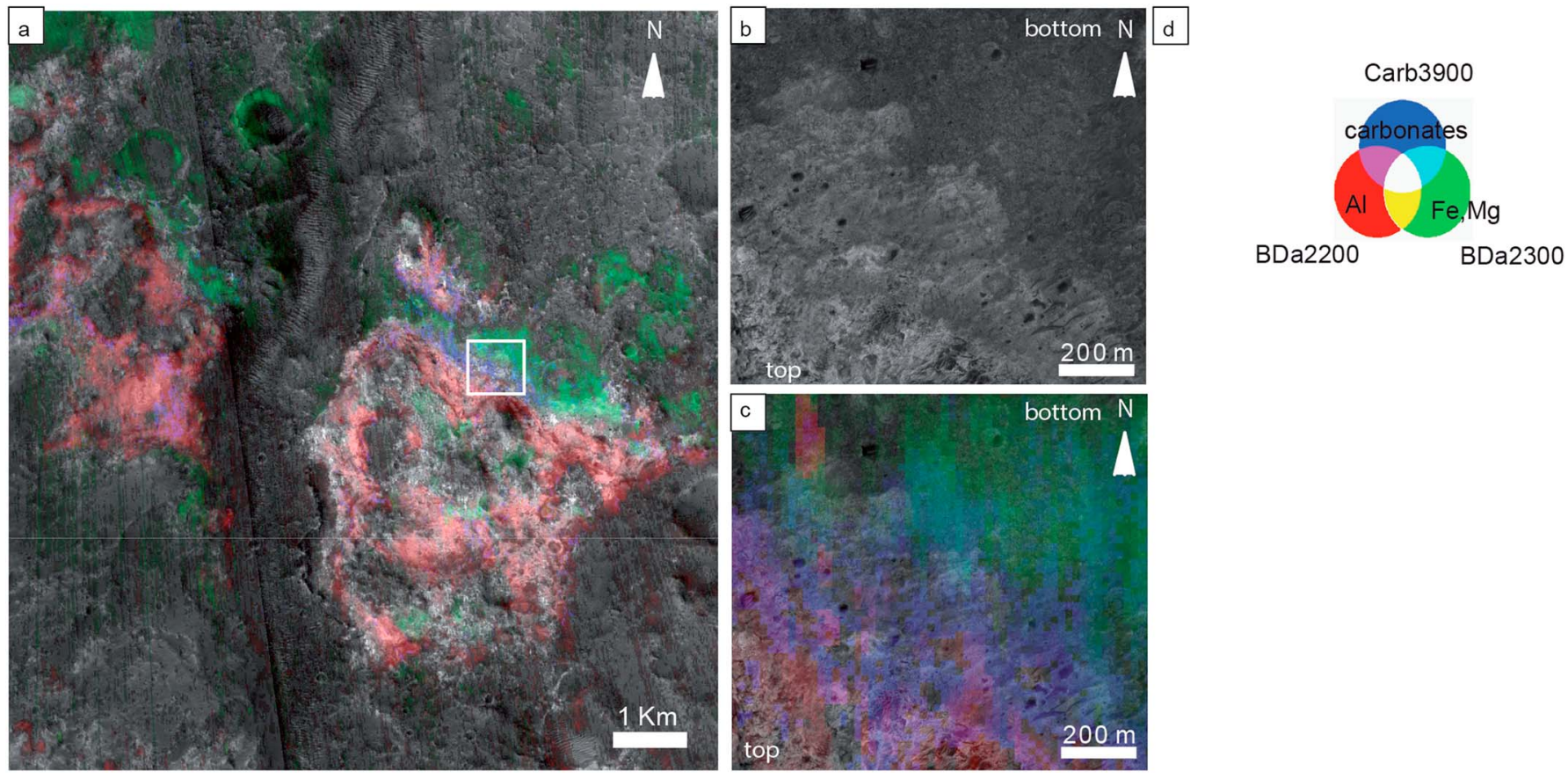

Figure 10. (a) CTX mosaic on Mawrth Vallis with overlapping CRISM image FRT00003BFB. The white rectangle identifies the zoom in (b) and (c). (b) HiRISE image PSP0020742025 on Mawrth Vallis. (c) Same as (b) but overlaid by a color composite of CRISM image FRT00003BFB. (d) Schematic color code of the mineral mapping $(\mathrm{red}=\mathrm{Al}$-rich clay minerals; green $=(\mathrm{Fe}, \mathrm{Mg})$-rich clay minerals; blue $=$ carbonates $)$ with the associated spectral parameters .

Mg-rich clay minerals and carbonates in the middle part of the sequence as seen in Mawrth Vallis. Figures 9a and $9 \mathrm{~b}$ illustrate a representative context of the North Hellas region. In this case, the weathering profile is present on the rim of a crater highly eroded. The highest part of the rim represents the top part of the weathering profile (highlighted in red with the color criteria used here). Figures $9 \mathrm{c}$ and $9 \mathrm{~d}$ show the context of the detections in Eridania Basin. This area has several topographic depressions exhibiting on their walls the weathering profiles as described before. The altered material is present in these depressions and appears brighter than the surrounding surface. The top part of the depressions represents the top part of the weathering profiles (Al-rich clay minerals, in red with the color criteria used here). The bottom part of the weathering profile is composed of carbonates and zeolite or sulfate. It appears blue at its top only because the carbonate presence is limited in the top part of this horizon. The bottom part of this horizon is not highlighted in Figures 9c and 9d. The distinction between the hydrated sulfates and the zeolites spectra is not possible because they are often similar (Carter et al., 2015).

Morphological investigation of the sequences provides additional information for their formation as shown by the best preserved site (Mawrth Vallis; Figure 10). There is no unconformity visible between the altered horizons at the HiRISE submeter scale. Across the horizons, similar polygonal-shaped fractures are present, and their exposed surfaces appear brighter than do those of the unaltered unit. All altered horizons resemble each other in texture and display a gradual spectral change of the mineralogy across the sequence. The three globally distributed sites, described here in detail, exhibit a similar sequence from Al-rich to Fe,Mg-rich clay mineral zones without any unconformity between these horizons. The bottom of the Fe,Mg-rich clay mineral horizon represents the weathering front separating the entire weathering profile from the basement unit (Figure 11). This description is sketched with the stratigraphy presented in Figure 11 where local variations in mineralogy from sites to sites are not represented.

\section{Discussion}

\subsection{Surface Weathering in a $\mathrm{CO}_{2}$-Rich Environment}

To better characterize the environment of weathering, we use here the mineral associations as a proxy and discuss the conditions of the system drawn from a terrestrial analog study (Gaudin et al., 2011), geochemical 


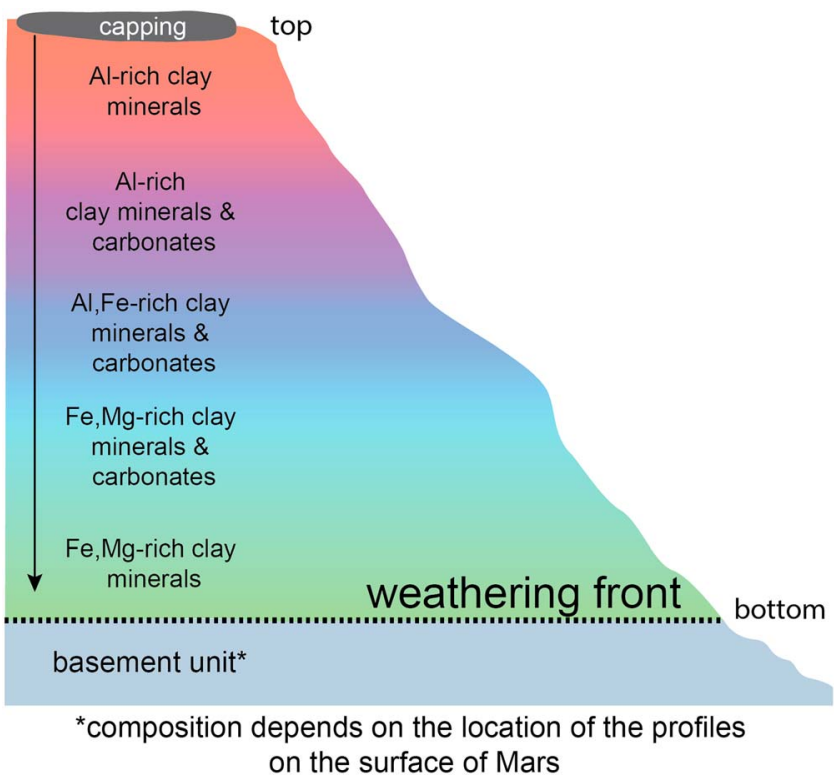

Figure 11. Sketch of the stratigraphic column (not at the scale) of the weathering profile. The dotted line indicates the weathering front between the Fe,Mg-rich clay minerals horizon and the basement. The black arrow symbolizes the progression of the weathering front. modeling (Zolotov \& Mironenko, 2016), and laboratory experiments (Gaudin et al., 2018; Viennet et al., 2017).

Carter et al. (2015) suggest that weathering with humid climate is the best explanation for the sequence from $\mathrm{Al}$ - to Fe,Mg-rich clay mineral. Indeed, the absence of high-temperature minerals in weathering profiles suggests that hydrothermalism is unlikely to be responsible for the sequences. Moreover, the presence of the stratigraphy at elevated altitudes is inconsistent with lacustrine/basin or any detrital deposits. As shown in the analog study of Gaudin et al. (2011), the sequence systematically consisting of Al-rich clay minerals on top of Fe,Mg-rich clay minerals and the lack of unconformities between the horizons show that weathering of a single basaltic unit from top to bottom without periods of erosion/deposition is the most likely process. Moreover, this stratigraphy indicates an evolution of the $\mathrm{pH}$ from acidic to neutral/alkaline conditions from the top to the bottom (Gaudin et al., 2011 and references therein; Zolotov \& Mironenko, 2016). Furthermore, carbonate precipitation only in part of the profiles can be explained by the $\mathrm{pH}$ increasing from the top to bottom of the weathering profiles as suggested by geochemical models (Zolotov \& Mironenko, 2016).

On Earth, pedogenic carbonates are common in arid to subhumid environments (Landi et al., 2003). Interestingly, carbonates often form from calcareous parent rock but are not restricted to this environment (Doner \& Lynn, 1989). For the formation of carbonates, cations (mostly calcium) are provided by dissolution of minerals and meteoric water percolation (Doner \& Lynn, 1989). On noncalcareous soils, carbon is supplied by vegetation, microbes, and atmosphere (Cerling \& Quade, 1993). Precipitation and dissolution of carbonates in soils is related to the $\mathrm{pCO}_{2}$ and water-rock ratio of the system (Doner \& Lynn, 1989). The latter is controlled by the climate (temperature and water availability) and the capacity of the water to interact with the protolith (e.g., porosity and slope; Doner \& Lynn, 1989). In arid climate, the carbonates are mostly present in the top horizon of the profiles, while in humid climate, the carbonates are dissolved in the top part and occur deeper in the profiles. In general, the more the leaching is important, the deeper the carbonates will be. In case of very strong leaching, carbonates can be completely removed from the profiles. Several parameters between current Earth and early Mars are extremely different. First, these weathering profiles are developed in volcanic rocks, not calcareous soils. Second, no vegetation is present on Mars, and the question of the presence of microbes remains hypothetic. These are two reasons to have less carbon in the system. Third, the tens of meters of some weathering profiles is not consistent with arid to subhumid environment. However, the high variation of thickness from one profile to another could reflect a variation of the mean precipitation. Finally, it is unlikely that the atmosphere to consider is the same. Hence, no comparison can be made with current soil formation on Earth. Elements of answer could come from weathering profiles formed on early Earth. However, paleoweathering profiles on Earth often suffered from later alteration (diagenesis, for example; i.e., Nesbitt \& Young, 1989). For these reasons, comparing paleoweathering profiles on Earth and on Mars is not straightforward. Therefore, the sole presence of carbonates in weathering profiles on Earth and Mars cannot be directly compared. We suggest here to conduct the discussion by using the mineralogical associations.

As explained in Zolotov \& Mironenko (2016), the initial pH and the composition of alteration solution can be assessed from minerals associated with phyllosilicates (e.g., sulfates, amorphous silica, and carbonates). Concerning the sulfates, their presence cannot be confirmed as a bottom layer here because of the similitude of the sulfate and zeolite spectra (see section 2.3 and Carter et al., 2015). Indeed, as explained in Carter et al. (2015), both zeolite and sulfate could have formed during the weathering profiles formation, either by precipitation or by accumulation. The bottom layer (of zeolite/sulfate mixed with carbonate) is not systematically present in all the weathering profiles studied here. However, sulfates, such as bassanite (Ca-sulfate; Wray et al., 2010) or jarosite (Fe-sulfate; Farrand et al., 2009, Pajola et al., 2016), have been detected locally in some of the weathering profiles (e.g., in Mawrth Vallis and Eridania Basin). None of these detections 
suggest that sulfates are present globally and systematically in one or multiple horizons of the weathering profiles. Amorphous silica is not clearly identified in this study but is suspected to be present at least in the Al-rich clay mineral horizon following previous studies (i.e., Bishop et al., 2013). Regarding the carbonates, we report here their presence in the middle part of the stratigraphy. In their models, Zolotov \& Mironenko (2016) show that carbonates can form under a wide range of $\mathrm{pCO}_{2}$ and that the $\mathrm{pCO}_{2}$ can only be determined due to the identification of the carbonate compositions and their amount. However, Zolotov and Mironenko (2016) show that more carbonates form at higher $\mathrm{pCO}_{2}$ and that the detectable amount of carbonates in the Martian weathering profiles suggests an elevated $\mathrm{pCO}_{2}$. Zolotov and Mironenko (2016) suggest that minor carbonates precipitate at depth from solution formed through neutralization of initially very low $\mathrm{pH}$ in a $\mathrm{CO}_{2}-\mathrm{H}_{2} \mathrm{SO}_{4}-\mathrm{HCl}$-rich fluid. The coformation of clay minerals and carbonates is possible when the solution becomes neutral. Ca-sulfates are predicted to form in the middle part of the profile, and $\mathrm{Mg}$-sulfate solutions are predicted to form in deeper part of the profile when the $\mathrm{pH}$ becomes neutral. Because none of the horizons in the weathering profiles are systematically composed of sulfates, the presence of sulfate ions might not be systematic in the formation of the weathering profiles. However the widespread presence of carbonates in the middle part of the profiles can suggest the presence of carbonate/bicarbonate ions in the alteration solution. Therefore, we suggest that the formation of the weathering profiles involved at least the presence of carbonic acid in the starting solution and possibly local presence of $\mathrm{H}_{2} \mathrm{SO}_{4}$ where sulfates are detected.

The experimental study of such system is challenged by the time needed to produce a significant amount of altered material. Nevertheless, a few studies have been performed (Gaudin et al., 2018, and references therein). Gaudin et al. (2018) reported experimental results of olivine weathering under a high- $\mathrm{pCO}_{2}$ atmosphere $\left(1\right.$ bar of $\mathrm{pCO}_{2}$ and between 15 and $\left.40{ }^{\circ} \mathrm{C}\right)$. The experiment in a high- $\mathrm{pCO}_{2}$ environment leads to the formation of amorphous silica, Al,Fe,Mg-rich clay minerals, and carbonates. Although at a high temperature, Viennet et al. (2017) experiments on basalt alteration in high- $\mathrm{pCO}_{2}$ environment demonstrate that depending on the $\mathrm{pCO}_{2}$, and its subsequent $\mathrm{pH}$, the alteration of a basaltic rock can lead to different associations of diverse $\mathrm{Al}, \mathrm{Fe}, \mathrm{Mg}$-rich clay minerals, carbonates, and zeolites. Finally, experimental results indicate that alteration in a high- $\mathrm{pCO}_{2}$ environment leads to the coprecipitation of clay minerals and carbonates. It also suggests that resulting mineralogical associations in such system is dependent on the $\mathrm{pH}$ induced (at least partly) by the $\mathrm{pCO}_{2}$. The previous idea why the carbonate was absent leads to suggest sulfuric acid as an acidic source (with low $\mathrm{pCO}_{2}$ ) for the formation of the weathering profiles (Zolotov \& Mironenko, 2016). However, the presently reported widespread presence of carbonates in the stratigraphy indicates that the alteration solution contained inorganic carbon. Hence, the weathering sequence is coherent with a chemical weathering involving inorganic carbon. Finally, taken together, experimental and modeling results tend to indicate an evolution from the top to bottom of the profiles of the dissolved inorganic carbon species and of the resulting $\mathrm{pH}$. Note that the initial (meteoritic water) $\mathrm{pH}$ and the solution composition could also have been controlled by other strong acids such as $\mathrm{HCl}$ and $\mathrm{H}_{2} \mathrm{SO}_{4}$ at least locally. While this is coherent with an atmosphere wetter and denser in $\mathrm{CO}_{2}$ than today, the undetermined species and amount of carbonates do not allow estimating the $\mathrm{pCO}_{2}$. Moreover, it does not exclude the presence of strong acids $\left(\mathrm{HCl}\right.$ and $\left.\mathrm{H}_{2} \mathrm{SO}_{4}\right)$ in meteoric waters.

\subsection{A Planetary-Scale Process}

In the following paragraph, we discuss the potentially planetary-scale character of the weathering profiles formed by fluids rich in carbonate/bicarbonate ions. Carter et al. (2015) have described that the process leading to the formation of the weathering profiles (i.e., composed of Al-rich clay minerals overlying Fe,Mg-rich clay minerals) was a planetary-scale phenomenon. However, our study describes the presence of the weathering profiles containing carbonates in specific regions that are less widespread than the profiles described in Carter et al. (2015; Figure 7). Several facts can explain the distribution of the weathering profiles and an underestimation of the number of clear and complete stratigraphies: (i) First, the limitation of the coverage of high-resolution CRISM data acquired before 2010 reduces our capacity to fully investigate all the weathering profiles described in Carter et al. (2015). (ii) An important part of the CRISM data cubes investigated in this study had a too low SNR to allow visualizing clearly a spectral gradual change from the top to bottom of the stratigraphy (Table 2). (iii) The presence of dust globally on the planet can hinder the investigation of the weathering sequence. (iv) The resurfacing by volcanic activity on the planet can have a buried part of the 
weathering profiles hiding them from remote sensing investigation, and we rely on erosion windows to detect and investigate the sequences. (v) The top layers of Al-rich clay minerals, Al-rich clay minerals with carbonates, and $\mathrm{Al}, \mathrm{Fe}-$ rich clays minerals with carbonates are generally thinner than the rest of the profiles. Hence, such horizons are more easily impacted by erosion, which explains the high proportion of partial stratigraphy present in some regions (Table 2). While, for example, Mawrth Vallis profiles were protected by a capping unit, this was not the case for other regions such as North Hellas where impact craters and erosion reduce the capacity to preserve a clear and complete stratigraphy. Finally, the overall widespread distribution of the profiles suggests a planetary-scale weathering with a fluid rich in dissolved inorganic carbon species and possibly locally together with other strong acids $\left(\mathrm{HCl}\right.$ and $\left.\mathrm{H}_{2} \mathrm{SO}_{4}\right)$ that affected the surface of Mars at least at the midlatitudes.

\subsection{Implications for the Geological Evolution of Mars}

Although we present here indications of a planetary-scale weathering related to a fluid rich in carbonate/bicarbonate ions, its coherence with regard to our present knowledge of the geological evolution of the planet should be addressed. The presence of a nonhydrated capping unit dated from around 3.7 Gyrs (Loizeau et al., 2012) allows dating the weathering process as a Noachian environment. It coincides well with morphological studies suggesting the Noachian as the most efficient period of water-related resurfacing processes (Quantin-Nataf et al., 2019; Werner et al., 2011). The presence of carbonates associated with planetary-scale weathering during its wetter period coincides well with climate models suggesting a denser $\mathrm{CO}_{2}$-rich atmosphere as a part of explanation for adequate conditions to have liquid water at the surface of Mars during the Noachian (Wordsworth et al., 2017). However, the sole detection of carbonates in the weathering profiles does not imply a $\mathrm{pCO}_{2}$ as high as what is suggested in Wordsworth et al. (2017). More in-depth investigation is needed to determine precisely the composition and amount of the carbonates to suggest any $\mathrm{pCO}_{2}$ values. Alternatively, the (late) presence of liquid water could be punctual and related to volcano or impact-generated climate optima (i.e., Wordsworth et al., 2013). We suggest that the observation of carbonates in these weathering profiles is a new important step to reconcile climatic models with the mineralogical and morphological interpretations. However, the debate of episodic periods of warm enough environment to sustain liquid water versus a permanent warm period over the entire Noachian cannot be solved here and neither is the reason for the end of the warm and wet conditions.

\subsection{Implications for Habitable Conditions on Mars}

Of note, we show that the weathering profiles constitute environments with diverse conditions (composition, $\mathrm{pH}$, and $\mathrm{pCO}_{2}$ ). Such chemical heterogeneity alerts interest for astrobiology as it encompasses both a diversity of potentially habitable environments and chemical gradients that are essential for microbial life metabolism (Cleaves, 2013). Moreover, an analog study on carbonates in the Mojave Desert by Bishop et al. (2011) suggests that carbonate rocks can provide protection of organic matter from solar radiation. However, weathering profiles are subject to loss of nutrients by leaching in the weathered part of the soil, and this could reduce their habitability potential (Duddy, 1980; Nesbitt \& Markovics, 1980). On the other hand, weathering profiles are known to have hosted life early on Earth and can be considered as of interest for astrobiology (ca. 3 billion years ago; Lenton \& Daines, 2017).

\section{Conclusion}

Using a new spectral criterion, we mapped the presence of carbonates mixed with various clay minerals in weathering profiles. We used the particular variation of the mineralogical assemblages (i.e., from top to bottom: Al-rich clay minerals, a mixture of Al-rich clay minerals and carbonates, Al,Fe-rich clay minerals mixed with carbonates, Fe,Mg-rich clay minerals mixed with carbonates, and finally, Fe,Mg-rich clay minerals) as a proxy to apprehend the conditions of the water-rock interactions. Our observations indicate that the profiles formed by a weathering containing inorganic carbon (and possibly strong acids) with a $\mathrm{pH}$ solution gradually increasing with depth within the sequence toward neutral/alkaline values on a planetary scale. Based on comparison with geochemical models, we suggest an elevated $\mathrm{pCO}_{2}$ to lead to the mineralogical sequence observed.

Future in situ investigation of the best preserved weathering profiles at Mawrth Vallis or on the margins of Eridania Basin should provide unprecedented details on the atmosphere composition and more specifically 
ancient atmospheric $\mathrm{CO}_{2}$ pressure, as well as the composition and evolution of the aqueous solution required to form these mineralogical associations.

\section{Acknowledgments}

We thank Mikhail Zolotov, Briony

Horgan, and an anonymous reviewer for their comments that greatly improved the quality of the manuscript. This study is supported by the Research Council of Norway in form of the 235058/F20 CRATER CLOCK project and through its Centers of Excellence funding scheme, project number 223272. This project has received funding from the European Union's Horizon 2020 (H2020-COMPET-2015) research and innovation program under the grant agreement no. 687302 (PTAL). The comparison between observed and library spectra are performed with the ASTER spectral library (Baldridge et al., 2009) (https://speclib.jpl.nasa.gov/ search-1). The CRISM data are available from the NASA Planetary Data System Geoscience Node (http://pdsgeosciences.wustl.edu/missions/mro/ crism.htm). CTX data are available at the Image Explorer on the Arizona State University website (http://viewer. mars.asu.edu/viewer/ctx\#T=0). HiRISE data are available from the University of Arizona HiRISE website (https://hirise.lpl.arizona.edu/). All CRISM, CTX, and HiRISE data are also provided through the MarsSI application (https://emars.univ-lyon1.fr/ MarsSI/). The MOLA data are available from the United States Geological Survey Planetary GIS Web Server (http://webgis.wr.usgs.gov/pigwad/ down/mars_dl.htm).

\section{References}

Allen, P. A. (1997). Earth surface processes. Malden, Massachusetts: John Wiley \& Sons. https://doi.org/10.1002/9781444313574 Amador, E. S., Bandfield, J. L., \& Thomas, N. H. (2018). A search for minerals associated with serpentinization across Mars using CRISM spectral data. Icarus, 311, 113-134. https://doi.org/10.1016/j.icarus.2018.03.021

Baldridge, A. M., Hook, S. J., Grove, C. I., \& Rivera, G. (2009). The ASTER spectral library version 2.0. Remote Sensing of Environment, 113(4), 711-715. https://doi.org/10.1016/j.rse.2008.11.007

Bishop, J. L., Fairen, A. G., Michalski, J. R., Gago-Duport, L., Baker, L. L., Velbel, M. A., et al. (2018). Surface clay formation during shortterm warmer and wetter conditions on a largely cold ancient Mars. Nature Astronomy, 2(3), 206-213. https://doi.org/10.1038/s41550017-0377-9

Bishop, J. L., Loizeau, D., McKeown, N. K., Saper, L., Dyar, M. D., Des Marais, D. J., et al. (2013). What the ancient phyllosilicates at Mawrth Vallis can tell us about possible habitability on early Mars. Planetary and Space Science, 86, 130-149. https://doi.org/10.1016/j. pss.2013.05.006

Bishop, J. L., Schelble, R. T., McKay, C. P., Brown, A. J., \& Perry, K. A. (2011). Carbonate rocks in the Mojave Desert as an analogue for Martian carbonates. International Journal of Astrobiology, 10(04), 349-358. https://doi.org/10.1017/S1473550411000206

Blaney, D. L., \& McCord, T. B. (1989). An observational search for carbonates on Mars. Journal of Geophysical Research, 94(B8), 10,159-10,166. https://doi.org/10.1029/JB094iB08p10159

Bonello, G., Bibring, J. P., Poulet, F., Gendrin, A., Gondet, B., Langevin, Y., \& Fonti, S. (2004). Visible and infrared spectroscopy of minerals and mixtures with the OMEGA/MARS-EXPRESS instrument. Planetary and Space Science, 52(1-3), 133-140. https://doi.org/10.1016/j. pss.2003.08.014

Boynton, W. V., Ming, D. W., Kounaves, S. P., Young, S. M. M., Arvidson, R. E., Hecht, M. H., et al. (2009). Evidence for calcium carbonate at the Mars Phoenix landing site. Science, 325(5936), 61-64. https://doi.org/10.1126/science.1172768

Brown, A. J., Hook, S. J., Baldridge, A. M., Crowley, J. K., Bridges, N. T., Thomson, B. J., et al. (2010). Hydrothermal formation of claycarbonate alteration assemblages in the Nili Fossae region of Mars. Earth and Planetary Science Letters, 297(1-2), 174-182. https://doi. org/10.1016/j.epsl.2010.06.018

Bultel, B., Quantin, C., \& Lozac'h, L. (2015). Description of CoTCAT (complement to CRISM analysis toolkit). IEEE Journal of Selected Topics in Applied Earth Observations and Remote Sensing, 8(6), 3039-3049. https://doi.org/10.1109/JSTARS.2015.2405095

Carrozzo, F. G., De Sanctis, M. C., Raponi, A., Ammannito, E., Castillo-Rogez, J., Ehlmann, B. L., et al. (2018). Nature, formation, and distribution of carbonates on Ceres. Science Advances, 4.3, e1701645.

Carter, J., Loizeau, D., Mangold, N., Poulet, F., \& Bibring, J. P. (2015). Widespread surface weathering on early Mars: A case for a warmer and wetter climate. Icarus, 248, 373-382. https://doi.org/10.1016/j.icarus.2014.11.011

Carter, J., Poulet, F., Bibring, J. P., Mangold, N., \& Murchie, S. (2013). Hydrous minerals on Mars as seen by the CRISM and OMEGA imaging spectrometers: Updated global view. Journal of Geophysical Research: Planets, 118, 831-858. https://doi.org/10.1029/ 2012JE004145

Cerling, T. E., \& Quade, J. (1993). Stable carbon and oxygen isotopes in soil carbonates. In P. K. Swart, K. C. Lohmann, J. McKenzie, \& S. Savin (Eds.), Climate change in continental isotopic records, Geophysical Monograph, (Vol. 78, pp. 217-231). Washington, DC: American Geophysical Union.

Clark, R. N., King, T. V., Klejwa, M., Swayze, G. A., \& Vergo, N. (1990). High spectral resolution reflectance spectroscopy of minerals. Journal of Geophysical Research, 95(B8), 12,653-12,680. https://doi.org/10.1029/JB095iB08p12653

Cleaves, H. (2013). Prebiotic chemistry: Geochemical context and reaction screening. Life, 3(2), 331-345. https://doi.org/10.3390/ life 3020331

Cloutis, E. A., Asher, P. M., \& Mertzman, S. A. (2002). Spectral reflectance properties of zeolites and remote sensing implications. Journal of Geophysical Research, (E9), 107, 5067. https://doi.org/10.1029/2000JE001467

Cloutis, E. A., Hawthorne, S. A. M., Krenn, K., Craig, M. A., Marcino, D., Methot, M., et al. (2006). Detection and discrimination of sulfate minerals using reflectance spectroscopy. Icarus, 184(1), 121-157. https://doi.org/10.1016/j.icarus.2006.04.003

De Angelis, S., Carli, C., Tosi, F., Beck, P., Brissaud, O., Schmitt, B., et al. (2019). NIR reflectance spectroscopy of hydrated and anhydrous sodium carbonates at different temperatures. Icarus, 317, 388-411. https://doi.org/10.1016/j.icarus.2018.08.012

De Sanctis, M. C., Ammannito, E., Raponi, A., Marchi, S., McCord, T. B., McSween, H. Y., et al. (2015). Ammoniated phyllosilicates with a likely outer solar system origin on (1) Ceres. Nature, 528(7581), 241-244. https://doi.org/10.1038/nature16172

De Sanctis, M. C., Raponi, A., Ammannito, E., Ciarniello, M., Toplis, M. J., McSween, H. Y., et al. (2016). Bright carbonate deposits as evidence of aqueous alteration on (1) Ceres. Nature, 536(7614), 54-57. https://doi.org/10.1038/nature18290

Doner, H. E., \& Lynn, W. C. (1989). Carbonate, halide, sulfate, and sulfide minerals. Minerals in Soil Environments, 279-330. https://doi. org/10.2136/sssabookser1.2ed.c6

Duddy, L. R. (1980). Redistribution and fractionation of rare-earth and other elements in a weathering profile. Chemical Geology, 30(4), 363-381. https://doi.org/10.1016/0009-2541(80)90102-3

Edwards, C. S., \& Ehlmann, B. L. (2015). Carbon sequestration on Mars. Geology, 43(10), 863-866. https://doi.org/10.1130/G36983.1

Ehlmann, B. L., Mustard, J. F., Murchie, S. L., Poulet, F., Bishop, J. L., Brown, A. J., et al. (2008). Orbital identification of carbonate-bearing rocks on Mars. Science, 322(5909), 1828-1832. https://doi.org/10.1126/science.1164759

Farrand, W. H., Glotch, T. D., Rice, J. W. Jr., Hurowitz, J. A., \& Swayze, G. A. (2009). Discovery of jarosite within the Mawrth Vallis region of Mars: Implications for the geologic history of the region. Icarus, 204(2), 478-488. https://doi.org/10.1016/j.icarus.2009.07.014

Gaffey, S. J. (1987). Spectral reflectance of carbonate minerals in the visible and near infrared (0.35-2.55 $\mu \mathrm{m})$ : Anhydrous carbonate minerals. Journal of Geophysical Research, 92(B2), 1429-1440. https://doi.org/10.1029/JB092iB02p01429

Gaudin, A., Dehouck, E., Grauby, O., \& Mangold, N. (2018). Formation of clay minerals on Mars: Insights from long-term experimental weathering of olivine. Icarus, 311, 210-223. https://doi.org/10.1016/j.icarus.2018.01.029

Gaudin, A., Dehouck, E., \& Mangold, N. (2011). Evidence for weathering on early Mars from a comparison with terrestrial weathering profiles. Icarus, 216(1), 257-268. https://doi.org/10.1016/j.icarus.2011.09.004

Goudge, T. A., Mustard, J. F., Head, J. W., \& Fassett, C. I. (2012). Constraints on the history of open-basin lakes on Mars from the composition and timing of volcanic resurfacing. Journal of Geophysical Research, 117, E00J21. https://doi.org/10.1029/2012JE004115 
Harner, P. L., \& Gilmore, M. S. (2015). Visible-near infrared spectra of hydrous carbonates, with implications for the detection of carbonates in hyperspectral data of Mars. Icarus, 250, 204-214. https://doi.org/10.1016/j.icarus.2014.11.037

Hexter, R. M. (1958). High-resolution, temperature-dependent spectra of calcite. Spectrochimica Acta, 10(3), 281-290. https://doi.org/ 10.1016/0371-1951(58)80094-6

Hopkinson, L., Kristova, P., \& Rutt, K. (2017). The near-infrared (NIR) spectra of powdered calcite in the 3-121 $\mu \mathrm{m}$ mode particle size range. Vibrational Spectroscopy, 90, 69-73. https://doi.org/10.1016/j.vibspec.2017.03.006

Howard, A. D., Moore, J. M., \& Irwin, R. P. III (2005). An intense terminal epoch of widespread fluvial activity on early Mars: 1. Valley network incision and associated deposits. Journal of Geophysical Research, 110, E12S14. https://doi.org/10.1029/2005JE002459

Hunt, G. R. (1977). Spectral signatures of particulate minerals in the visible and near infrared. Geophysics, 42(3), 501-513. https://doi.org/ $10.1190 / 1.1440721$

Hunt, G. R., \& Salisbury, J. W. (1971). Visible and near infrared spectra of minerals and rocks. II. Carbonates. Modern Geology, 2, 23-30.

Landi, A., Mermut, A. R., \& Anderson, D. W. (2003). Origin and rate of pedogenic carbonate accumulation in Saskatchewan soils, Canada Geoderma, 117(1-2), 143-156. https://doi.org/10.1016/S0016-7061(03)00161-7

Langevin, Y., Poulet, F., Bibring, J. P., \& Gondet, B. (2005). Sulfates in the north polar region of Mars detected by OMEGA/Mars Express. Science, 307(5715), 1584-1586. https://doi.org/10.1126/science.1109091

Lenton, T. M., \& Daines, S. J. (2017). Matworld-The biogeochemical effects of early life on land. New Phytologist, 215(2), 531-537. https:// doi.org/10.1111/nph.14338

Loizeau, D., Werner, S. C., Mangold, N., Bibring, J. P., \& Vago, J. L. (2012). Chronology of deposition and alteration in the Mawrth Vallis region, Mars. Planetary and Space Science, 72(1), 31-43. https://doi.org/10.1016/j.pss.2012.06.023

McGuire, P. C., Bishop, J. L., Brown, A. J., Fraeman, A. A., Marzo, G. A., Morgan, M. F., \& Roush, T. L. (2009). An improvement to the volcano-scan algorithm for atmospheric correction of CRISM and OMEGA spectral data. Planetary and Space Science, 57(7), 809-815. https://doi.org/10.1016/j.pss.2009.03.007

Morris, R. V., Ruff, S. W., Gellert, R., Ming, D. W., Arvidson, R. E., Clark, B. C., et al. (2010). Identification of carbonate-rich outcrops on Mars by the Spirit rover. Science, 1189667.

Murchie, S., Arvidson, R., Bedini, P., Beisser, K., Bibring, J.-. P., Bishop, J., et al. (2007). Compact Reconnaissance Imaging Spectrometer for Mars (CRISM) on Mars Reconnaissance Orbiter (MRO). Journal of Geophysical Research, 112, E05S03. https://doi.org/10.1029/ 2006JE002682

Navarre-Sitchler, A., \& Brantley, S. (2007). Basalt weathering across scales. Earth and Planetary Science Letters, 261(1-2), 321-334. https:// doi.org/10.1016/j.epsl.2007.07.010

Nesbitt, H. W., \& Markovics, G. (1980). Chemical processes affecting alkalis and alkaline earths during continental weathering. Geochimica et Cosmochimica Acta, 44(11), 1659-1666. https://doi.org/10.1016/0016-7037(80)90218-5

Nesbitt, H. W., \& Young, G. M. (1989). Formation and diagenesis of weathering profiles. The Journal of Geology, 97(2), 129-147. https://doi org/10.1086/629290

Pajola, M., Rossato, S., Carter, J., Baratti, E., Pozzobon, R., Erculiani, M. S., et al. (2016). Eridania Basin: An ancient paleolake floor as the next landing site for the Mars 2020 rover. Icarus, 275, 163-182. https://doi.org/10.1016/j.icarus.2016.03.029

Palomba, E., Longobardo, A., De Sanctis, M. C., Stein, N. T., Ehlmann, B., Galiano, A., et al. (2017). Compositional differences among bright spots on the Ceres surface. Icarus, 320, 202-212.

Parente, M. (2008). A new approach to denoising CRISM images. In Lunar and Planetary Science Conference (Vol. 39, p. 2528).

Pelkey, S. M., Mustard, J. F., Murchie, S., Clancy, R. T., Wolff, M., Smith, M., et al. (2007). CRISM multispectral summaryproducts: Parameterizing mineral diversity on Mars from reflectance. Journal of Geophysical Research, 112, E08S14.

Pinti, D. (2011). Weathering profile. In Encyclopedia of astrobiology, (pp. 1778-1778). Berlin, Heidelberg: Springer. https://doi.org/10.1007/ 978-3-642-11274-4_1865

Quantin-Nataf, C., Craddock, R. A., Dubuffet, F., Lozac'h, L., \& Martinot, M. (2019). Decline of crater obliteration rates during early Martian history. Icarus, 317, 427-433. https://doi.org/10.1016/j.icarus.2018.08.005

Quantin-Nataf, C., Lozac'h, L., Thollot, P., Loizeau, D., Bultel, B., Fernando, J., et al. (2018). MarsSI: Martian surface data processing information system. Planetary and Space Science, 150, 157-170.

Righi, D., \& Meunier, A. (1995). Origin of clays by rock weathering and soil formation. In Origin and mineralogy of clays, (pp. 43-161). Berlin: Heidelberg Springer.

Roush, T. (2010). Estimation of visible, near-, and mid-infrared optical constants of dolomite. In European Planetary Science Congress Abstracts, 5, 341.

Ruff, S. W., Niles, P. B., Alfano, F., \& Clarke, A. B. (2014). Evidence for a Noachian-aged ephemeral lake in Gusev crater, Mars. Geology, 42(4), 359-362. https://doi.org/10.1130/G35508.1

Salisbury, J. W., Hapke, B., \& Eastes, J. W. (1987). Usefulness of weak bands in midinfrared remote sensing of particulate planetary surfaces. Journal of Geophysical Research, 92(B1), 702-710. https://doi.org/10.1029/JB092iB01p00702

Salisbury, J. W., \& Walter, L. S. (1989). Thermal infrared $(2.5-13.5 \mu \mathrm{m})$ spectroscopic remote sensing of igneous rock types on particulate planetary surfaces. Journal of Geophysical Research, 94(B7), 9192-9202. https://doi.org/10.1029/JB094iB07p09192

Schaefer, M. W. (1990). Geochemical evolution of the northern plains of Mars: Early hydrosphere, carbonate development, and present morphology. Journal of Geophysical Research, 95(B9), 14,291-14,300. https://doi.org/10.1029/JB095iB09p14291

Sutter, B., Dalton, J. B., Ewing, S. A., Amundson, R., \& McKay, C. P. (2007). Terrestrial analogs for interpretation of infrared spectra from the Martian surface and subsurface: Sulfate, nitrate, carbonate, and phyllosilicate-bearing Atacama Desert soils. Journal of Geophysical Research, 112, G04S10. https://doi.org/10.1029/2006JG000313

Velde, B. B., \& Meunier, A. (2008). The origin of clay minerals in soils and weathered rocks. Berlin-Heidelberg: Springer Science \& Business Media. https://doi.org/10.1007/978-3-540-75634-7

Viennet, J.-C., Bultel, B., Riu, L., \& Werner, S. (2017). Dioctahedral phyllosilicates/zeolites versus carbonates/zeolites competitions as constraints to understand early Mars alteration conditions. Journal of Geophysical Research: Planet, 122, 2328-2343. https://doi.org/ 10.1002/2017JE005343

Viviano, C. E., Moersch, J. E., \& McSween, H. Y. (2013). Implications for early hydrothermal environments on Mars through the spectral evidence for carbonation and chloritization reactions in the Nili Fossae region. Journal of Geophysical Research: Planets, 118, 1858-1872. https://doi.org/10.1002/jgre.20141

Viviano-Beck, C. E., Seelos, F. P., Murchie, S. L., Kahn, E. G., Seelos, K. D., Taylor, H. W., et al. (2014). Revised CRISM spectral parameters and summary products based on the currently detected mineral diversity on Mars. Journal of Geophysical Research: Planets, 119, 1403-1431. https://doi.org/10.1002/2014JE004627 
Wagner, C., \& Schade, U. (1996). Measurements and calculations for estimating the spectrometric detection limit for carbonates in Martian soil. Icarus, 123(2), 256-268. https://doi.org/10.1006/icar.1996.0156

Werner, S. C., Tanaka, K. L., \& Skinner, J. A. Jr. (2011). Mars: The evolutionary history of the northern lowlands based on crater counting and geologic mapping. Planetary and Space Science, 59(11-12), 1143-1165. https://doi.org/10.1016/j.pss.2011.03.022

Williams, R. M., Grotzinger, J. P., Dietrich, W. E., Gupta, S., Sumner, D. Y., Wiens, R. C., et al. (2013). Martian fluvial conglomerates at Gale crater. Science, 340(6136), 1068-1072. https://doi.org/10.1126/science.1237317

Wordsworth, R., Forget, F., Millour, E., Head, J. W., Madeleine, J. B., \& Charnay, B. (2013). Global modelling of the early Martian climate under a denser $\mathrm{CO}_{2}$ atmosphere: Water cycle and ice evolution. Icarus, 222(1), 1-19. https://doi.org/10.1016/j.icarus.2012.09.036

Wordsworth, R., Kalugina, Y., Lokshtanov, S., Vigasin, A., Ehlmann, B., Head, J., et al. (2017). Transient reducing greenhouse warming on early Mars. Geophysical Research Letters, 44, 665-671. https://doi.org/10.1002/2016GL071766

Wray, J. J., Murchie, S. L., Bishop, J. L., Ehlmann, B. L., Milliken, R. E., Wilhelm, M. B., et al. (2016). Orbital evidence for more widespread carbonate-bearing rocks on Mars. Journal of Geophysical Research: Planets, 121, 652-677. https://doi.org/10.1002/2015JE004972

Wray, J. J., Squyres, S. W., Roach, L. H., Bishop, J. L., Mustard, J. F., \& Noe Dobrea, E. Z. (2010). Identification of the Ca-sulfate bassanite in Mawrth Vallis, Mars. Icarus, 209(2), 416-421. https://doi.org/10.1016/j.icarus.2010.06.001

Zolotov, M. Y., \& Mironenko, M. V. (2016). Chemical models for Martian weathering profiles: Insights into formation of layered phyllosilicate and sulfate deposits. Icarus, 275, 203-220. https://doi.org/10.1016/j.icarus.2016.04.011 